\title{
Advances in Age-related Macular Degeneration Understanding and Therapy
}

Joan W Miller, Saghar Bagheri, and Demetrios G Vavvas

Retina Service, Department of Ophthalmology, Massachusetts Eye and Ear, Harvard Medical School, Boston, MA, US

DOl: https://doi.org/10.17925/USOR.2017.10.02.119

W hile the development of anti-vascular endothelial growth factor (anti-VEGF) as a therapy for neovascular age-related macular degeneration (AMD) was a great success, the pathologic processes underlying dry AMD that eventually leads to photoreceptor dysfunction, death, and vision loss remain elusive to date, with a lack of effective therapies and increasing prevalence of the disease. There is an overwhelming need to improve the classification system of AMD, to increase our understanding of cell death mechanisms involved in both neovascular and non-neovascular AMD, and to develop better biomarkers and clinical endpoints to eventually be able to identify better therapeutic targets - especially early in the disease process. There is no doubt that it is a matter of time before progress will be made and better therapies will be developed for non-neovascular AMD.

\section{Keywords}

Age-related macular degeneration (AMD), neuroprotection, biomarkers, anti-vascular endothelial growth factor (VEGF), complement inhibition, statin

Disclosure: Joan W Miller has provided consulting for Alcon (serving on the Alcon Research Institute committee), Amgen, Inc., KalVista Pharmaceuticals, Ltd., Maculogix, Inc., and ONL Therapeutics within the last 12 months. She is a named inventor on patents/patent applications on methods and compositions for preserving photoreceptor viability (assigned to Massachusetts Eye and Ear; licensed to ONL Therapeutics) and receives a share of the financial remuneration related to the proprietary interest of Massachusetts Eye and Ear in photodynamic therapy for conditions involving unwanted ocular neovascularization (licensed to Valeant Pharmaceuticals); however, Joan W Miller has nothing to declare in relation to this article. Saghar Bagheri and Demetrios $\mathrm{G}$ Vavvas have nothing to declare in relation to this article.

Acknowledgements: This work was supported by: NEI R21EY023079-01A1, R01EY025362-01 (DGV); the Yeatts Family Foundation (DGV, JWM); the Loefflers Family Fund (DGV, JWM); the 2013 Macula Society Research Grant award (DGV); a Physician Scientist Award from Research to Prevent Blindness (DGV), the Alcon Research Institute Young Investigator Award (DGV), an unrestricted grant from Research to Prevent Blindness (JWM), and the Champalimaud Vision Award (JWM). None of the aforementioned funding organizations had any role in publication of this article. The authors would also like to thank Christina Kaiser Marko for editorial assistance and support.

Compliance with Ethics: This study involves a review of the literature and did not involve any studies with human or animal subjects performed by any of the authors.

Authorship: All named authors meet the International Committee of Medical Journal Editors (ICMJE) criteria for authorship of this manuscript, take responsibility for the integrity of the work as a whole, and have given final approval to the version to be published.

open Access: This article is published under the Creative Commons Attribution Noncommercial License, which permits any noncommercial use, distribution, adaptation, and reproduction provided the original author(s) and source are given appropriate credit.

Received: September 28, 2017

Accepted: October 16, 2017

Citation: US Ophthalmic Review, 2017;10(2):119-30

Corresponding Author: Joan W Miller, Retina Service, Massachusetts Eye and Ear, Department of Ophthalmology, Harvard Medical School, 243 Charles Street, Ste. 800, Boston, MA 02114, US. E: joan_miller@meei.harvard.edu
Age-related macular degeneration (AMD) is the third leading cause of blindness worldwide and the primary leading cause of vision loss in the Western world. Its prevalence is expected to increase as a consequence of an aging population, such that it is estimated that close to 288 million people will be affected by AMD by 2040. ${ }^{1}$ AMD presents in two major forms: the non-neovascular, non-exudative "dry" form affecting 85-90\% of patients and the neovascular, exudative "wet" form affecting 10-15\% of patients. Up until the late 1990s, treatment for AMD was limited to destructive thermal laser therapy for the neovascular form. In the last two decades, we have experienced a renaissance with more targeted approaches for the treatment of neovascular AMD. Liposomal verteporfinbased photodynamic therapy (Visudyne ${ }^{\circledR}$ ) was used to selectively close choroidal neovascularizations (CNV) - it is the first pharmacotherapy for AMD that is able to reduce and slow vision loss. ${ }^{2}$ Further work to understand the biological process of new vessel development, and demonstration of the key role of vascular endothelial growth factor (VEGF) led to extremely effective therapies, revolutionizing the treatment of neovascular AMD and preserving sight for millions of people. ${ }^{3}$ Subsequently, anti-VEGF therapy was applied to other diseases with abnormal angiogenesis and vascular leakage, including diabetic retinopathy, retinal vein occlusions, and pathologic myopic neovascularization, among others.

However, the pathologic processes underlying dry AMD remain elusive to date, with a lack of effective therapies. Non-exudative AMD is characterized by accumulation of deposits under the retinal pigment epithelium (RPE) and neurosensory retina, as well as degeneration of the RPE, photoreceptors, and even the choroidal vasculature. All of these ultimately lead to photoreceptor dysfunction, death, and vision loss. Although epidemiological and genetic studies have identified several candidates for the formation and progression of dry AMD, they also point to involvement of multiple biological pathways, including: lipid metabolism and transport regulation, inflammation (especially the complement system), extracellular matrix remodeling, cell adhesion, cellular toxicity, cell death, and angiogenesis. However, there is a lack of a unifying hypothesis that can explain how the disease starts and progresses - the causes of RPE and photoreceptor degeneration and loss remain obscure. The failure in truly understanding 
the pathogenesis of the disease, the lack of effective therapies, and the increasing prevalence all underscore a significant unmet clinical need. There is an overwhelming importance to address this issue by improving our classification system, identifying better therapeutic targets-especially early in the disease process - and developing better biomarkers and clinical endpoints.

\section{Current classification and characterization of age-related macular degeneration}

Several classification schemes of AMD have been developed, mostly based on color fundus photos. The most well known is the system used in the Age-Related Eye Disease Study (AREDS) study that classified AMD into early, intermediate, and late stage, accordingly. ${ }^{4}$ Early-stage AMD is defined by the presence of a few medium-size drusen and pigmentary abnormalities such as hyperpigmentation or hypopigmentation; intermediate-stage AMD is defined by the presence of at least one large druse, numerous mediumsize drusen, or geographic atrophy (GA) that does not extend to the center of the macula. ${ }^{5}$ Currently, early and intermediate AMD are only treated with AREDS-based vitamin supplementation. Late-stage AMD can be divided into advanced non-neovascular AMD and neovascular AMD. Advanced non-neovascular AMD is marked by drusen and GA extending to the center of the macula, while neovascular AMD is characterized by CNV and any of its potential sequelae-subretinal fluid, lipid deposition, hemorrhage, RPE detachment, and/or fibrotic scarring.

Despite the impact of the AREDS study on both the classification of the disease and treatment with vitamin supplementation for the disease, consensus is still lacking among physicians regarding terminology for the staging and progression of the disease. To tackle this, a new proposed scheme of clinical classification was put forward in 2013 by the Beckman Initiative for Macular Research Classification Committee, proposing 3 stages of the disease and one for a normal, aging phenotype (only small drusen $<63 \mu \mathrm{m}$ without pigment changes). ${ }^{6}$ They defined early AMD by the presence of medium drusen (>63 $\mu \mathrm{m} ; \leq 125 \mu \mathrm{m})$ and no AMD pigmentary abnormalities. The presence of large drusen and/ or any pigmentary changes was considered intermediate stage, and advanced stage disease was characterized by presence of any CNV or GA (see Table 1). It is important to note that this classification is also based on fundus photography and does not include information from other imaging modalities_optical coherence tomography (OCT), autofluorescence, or wide field imaging - and does not account for the presence of subretinal drusenoid deposits. Race, genetic, or environmental information is not included in the classification scheme, nor is it necessarily based on biological pathogenic processes.

While the late stages of AMD seem to converge into common pathogenesis pathways such as cell senescence and death in non-neovascular AMD, and angiogenesis in neovascular AMD, it appears that different biological pathways (lipids, autophagy, inflammation) may predominate in early- and intermediate-stage AMD. Thus, it is interesting that some clinical trials have aimed to target specific early biological pathways (such as inflammation and complement) to halt late stages of the disease such as progression of GA. It is possible that interventions of this type are ineffective this late in the disease course. By this time, we may need to consider approaches to inhibit cell death. Targeting underlying disease biological processes should occur in the early/intermediate stages and should include approaches involving lipid metabolism and transport, inflammation and complement,
Table 1: New Beckman staging of age-related macular degeneration and how it compares to Age-Related Eye Disease Study (AREDS) simplified grading scores and AREDS classification

\begin{tabular}{|c|c|c|c|}
\hline \multicolumn{2}{|l|}{ Beckman } & $\begin{array}{l}\text { AREDS } \\
\text { simplified } \\
\text { score }\end{array}$ & $\begin{array}{l}\text { AREDS } \\
\text { classification/ } \\
\text { categories }\end{array}$ \\
\hline No disease & No drusen no pigment chanegs & 0 & No disease \\
\hline $\begin{array}{l}\text { Normal } \\
\text { aging }\end{array}$ & $\leq 63$ drusen. Called druplets & 0 & $\begin{array}{l}\text { No disease or } \\
\text { early stage }\end{array}$ \\
\hline Early & $\begin{array}{l}>63 \leq 125 \mu \mathrm{m} \text { drusen and no } \\
\text { pigmentary changes }\end{array}$ & 0 & $\begin{array}{l}\text { Early or } \\
\text { intermediate }\end{array}$ \\
\hline Intermediate & $\begin{array}{l}>125 \mu \text { m drusen and/or } \\
\text { pigmentary changes }\end{array}$ & $1-4$ & Intermediate \\
\hline Advanced & Neovascular or geographic atrophy & $n / a, 5$ & Advanced \\
\hline
\end{tabular}

The Beckman Initiative Classification can be found in Ophthalmology, 2013 Apr;120:84451. The AREDS simplified score assigns 1 point per eye for the presence of either one of the recognized risk factors (large drusen or pigment changes). Detailed info can be found in Arch Ophthalmol, 2005 Nov;123:1570. For the AREDS staging or categories, please see https://nei.nih.gov/amd/background.

and cellular aging and senescence. Advanced stage (CNV, GA) targets should include anti-angiogenesis (anti-VEGF and neovascularization maturation) and anti-cell death (neuroprotection), respectively. Data also show that while re-classification of AMD based on biological processes is necessary, development of biomarkers to identify therapeutic targets for different subtypes of early and intermediate AMD is also critical.

\section{Targeting lipids in age-related macular degeneration}

One of the sine qua non of AMD is the accumulation of lipid-rich basal laminar deposits and drusen; it is thought that at least $40 \%$ of drusen volume is comprised of lipids.? Unlike atherosclerosis, serum low-density lipoprotein (LDL) levels in AMD do not have a strong association. ${ }^{8}$ However, there are certainly similarities between these two diseases. A number of studies have shown a link between cardiovascular risk factors and AMD, ${ }^{9-13}$ as well as several shared susceptibility genes. In addition, genome-wide association studies (GWAS) of AMD patients have identified several lipid metabolism-related genes (Table 2). ${ }^{14-16}$

Even before we had the genetic and epidemiological evidence for shared pathogenic mechanisms in cardiovascular disease and AMD, histopathologic data pointed to similarities between these two diseases. ${ }^{17}$ Bruch's membrane forms the inner margin of choriocapillaris and is considered an analog of the vascular intima sharing similar changes with aging. Similarities in molecular composition between drusen and atherosclerotic deposits lend further support to this concept. In both conditions, there is cholesterol and Apolipoprotein B (ApoB) accumulation with subsequent oxidation and modification. Drusen components are derived from local sources (retina/ RPE secretion of ApoB and ApoE lipoproteins) and, to a lesser extent, from the circulation. The retention of lipids leads to the formation of a lipid wall, basal linear deposits (BlinD), and drusen (Figure 1).

Given the many similarities between AMD and atherosclerosis, there have been several epidemiological studies investigating the role of statins in AMD. Previous studies examining the effect of statins on AMD status or the ability of statins to alter disease progression showed mixed results. Van der 
Table 2: Age-related macular degeneration and genes involved in lipid metabolism

\begin{tabular}{|c|c|}
\hline Gene, Location \& SNP & Function \\
\hline $\begin{array}{l}\text { ATP-BINDING CASSETTE, } \\
\text { SUBFAMILY A, MEMBER } 1 \\
\text { (ABCA1); 9q31.1; } \\
\text { rs1883025 }\end{array}$ & $\begin{array}{l}\text { Lipid transporter. Involved in cholesterol efflux pump } \\
\text { in the cellular lipid removal pathway. Alterations in } \\
\text { the ABCA1 gene have been associated with changes } \\
\text { in plasma HDL and LDL; in one extreme situation } \\
\text { (Tangier disease) levels of HDL are almost zero and } \\
\text { massive tissue deposition of cholesteryl esters are } \\
\text { observed. }\end{array}$ \\
\hline $\begin{array}{l}\text { ATP-BINDING CASSETTE, } \\
\text { SUBFAMILY A, } \\
\text { MEMBER } 4 \text { (ABCA4); } \\
\text { 1p22.1; rs61750130 }\end{array}$ & $\begin{array}{l}\text { Exclusively expressed in retinal photoreceptors. Is } \\
\text { involved in clearance from photoreceptor cells of all- } \\
\text { trans-retinal aldehyde. Mutations in ABCA4 result in } \\
\text { early onset macular degeneration of Stargardt's type }\end{array}$ \\
\hline $\begin{array}{l}\text { APOLIPOPROTEIN E (APOE); } \\
\text { 19q13.32; rs429358/rs7412 } \\
\text { haplotypes }\end{array}$ & $\begin{array}{l}\text { Maintains normal lipid homeostasis. Recognition site } \\
\text { for receptors involved in the clearance of remnants } \\
\text { of very low density lipoproteins and chylomicrons, } \\
\text { which are important for maintaining normal lipid } \\
\text { homeostasis. }\end{array}$ \\
\hline $\begin{array}{l}\text { CHOLESTERYL ESTER } \\
\text { TRANSFER PROTEIN (CETP); } \\
\text { 16q13; rs3764261 }\end{array}$ & $\begin{array}{l}\text { Mediates the exchange of lipids between } \\
\text { lipoproteins, resulting in the net transfer of } \\
\text { cholesteryl ester from high density lipoproteins } \\
\text { (HDL) to other lipoproteins and in the subsequent } \\
\text { uptake of cholesterol by hepatocytes. Deficiency of } \\
\text { CETP results in elevated HDL levels. Although the } \\
\text { exact effect of the AMD CEPT polymorphism on the } \\
\text { enzyme activity remains unclear, it is interesting to } \\
\text { note that the ALIENOR study and others have shown } \\
\text { an increased risk of AMD in patients with elevated } \\
\text { serum HDL. }\end{array}$ \\
\hline $\begin{array}{l}\text { HEPATIC LIPASE (LIPC); } \\
\text { 15q21.3; rs10468017 }\end{array}$ & $\begin{array}{l}\text { Encodes hepatic lipase, an enzyme that hydrolyzes } \\
\text { fatty acyl chains of phospholipids and acylglycerols } \\
\text { associated with various lipoproteins (including } \\
\text { HDL). May facilitate cholesteryl ester uptake from } \\
\text { lipoproteins. }\end{array}$ \\
\hline $\begin{array}{l}\text { CYTOCHROME P450, } \\
\text { FAMILY 24, SUBFAMILY A, } \\
\text { POLYPEPTIDE } 1 \text { (CYP24A1); } \\
\text { 20q13.2 }\end{array}$ & $\begin{array}{l}\text { Encodes a mitochondrial enzyme involved in Vit. D } \\
\text { inactivation by hydroxylation at position 24. Animals } \\
\text { with constitutive expression of CYP24 showed not } \\
\text { only changes in Vitamin D levels, but also developed } \\
\text { albuminuria and hyperlipidemia and all lipoprotein } \\
\text { fractions are elevated. }\end{array}$ \\
\hline $\begin{array}{l}\text { RAR-RELATED ORPHAN } \\
\text { RECEPTOR A (RORA); } \\
15 q 22.2\end{array}$ & $\begin{array}{l}\text { Member of a new subfamily of the steroid hormone } \\
\text { nuclear receptor superfamily (includes receptors } \\
\text { for steroids, retinoids, and thyroid hormones, and } \\
\text { related 'orphan' receptors with unknown ligands). } \\
\text { Cholesterol is one of the natural ligands, implicating } \\
\text { RORA in inflammatory processes and lipoprotein } \\
\text { metabolism. }\end{array}$ \\
\hline $\begin{array}{l}\text { BRAIN-SPECIFIC } \\
\text { ANGIOGENESIS INHIBITOR } \\
1 \text { (BAI1)-ASSOCIATED } \\
\text { PROTEIN 2-LIKE } 2 \\
\text { (BAIAP2L2); 22q13.1 }\end{array}$ & $\begin{array}{l}\text { AlsO called PLANAR INTESTINE- AND KIDNEY- } \\
\text { SPECIFIC BAR DOMAIN PROTEIN, binds } \\
\text { phosphoinositides and promotes formation of planar } \\
\text { or curved membrane structures. }\end{array}$ \\
\hline
\end{tabular}

Beek et al. showed that increased serum LDL and triglycerides, plus more than 1 year of statin use, led to increased risk of neovascular AMD while a meta-analysis by Klein et al. of three cohorts showed no association of AMD incidence or progression with serum lipids, statin use, or lipid pathway
Figure 1: Hypothetical schematic of lipid deposit progression and drusen formation in age-related macular degeneration
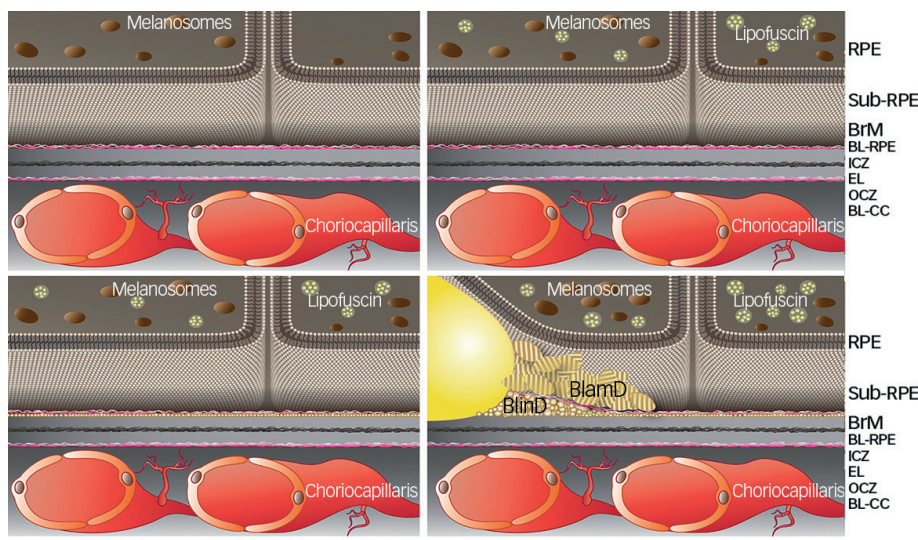

Adapted from Miller JW, Age-related macular degeneration revisited-piecing the puzzle: the LXIX Edward Jackson memorial lecture, Am J Ophthalmol, 2013;155:1-35.e13. Copyright 2013 Elsevier, Inc.

genes. $^{18,19}$ A small, proof-of-concept, randomized, placebo-controlled study suggested that daily simvastatin at $40 \mathrm{mg}$ (equivalent to $20 \mathrm{mg}$ atorvastatin) may slow progression of early/intermediate AMD in patients with complement factor H (CFH) genotype CC (Y402H). ${ }^{20}$ A 2016 Cochrane review concluded that there is insufficient evidence to conclude that statins play a role in preventing or delaying the onset or progression of AMD. ${ }^{21}$ All of these studies are limited by AMD disease heterogeneity and a lack of standardization of statin dosages or lipophilicity. A review of cardiovascular literature suggested that statin dosage affects outcome-low/moderate doses showed decreases in disease progression, ${ }^{22-27}$ whereas high-dose (80 mg) atorvastatin led to regression of atheromas. ${ }^{28-30}$

A small pilot phase I/II study of high-dose atorvastatin (80 mg) in selected patients with large soft drusenoid deposits/pigment epithelial detachments (PEDs) showed regression of drusenoid deposits in ten out of 23 patients with an average follow-up time of about 1.5 years. ${ }^{31}$ Responders had stable or slightly improved vision. None of the study patients developed atrophy or progressed to neovascular AMD. Possible mechanisms of statin therapy could include changes in RPE lipoprotein metabolism, creation of a systemic permissive state for lipid efflux, improvement of macrophage lipid clearing status, as well as anti-inflammatory and protective effects on RPE and antiangiogenic effects. The results of this pilot study are consistent with the "oil spill" hypothesis proposed by Curcio and colleagues, ${ }^{17}$ and suggest for the first time that this disease can be reversed anatomically and functionally (Figure 2). These results need to be confirmed in larger randomized studies that will include genetic analysis, lipid sub-species measurements, and functional studies, such as dark adaptation.

\section{Inflammation and Immunity}

Aging and lipids are required for AMD but are probably not sufficient to cause AMD. Inflammation and immune dysfunction appear to be required as well, and multiple genes involved in inflammation have been associated with AMD (Table 3).

Inflammation appears to be central to all stages of AMD. However, it is likely not classic inflammation, but rather a "para-inflammation"-a low-grade inflammation responding to aging and other insults. ${ }^{32}$ While it is thought that some level of para-inflammation may be helpful, at 
Figure 2: Spectral domain optical coherence tomography findings showing regression of drusenoid pigment epithelium detachments after high-dose atorvastatin $(80 \mathrm{mg}$ ) without atrophy of retinal pigment epithelium

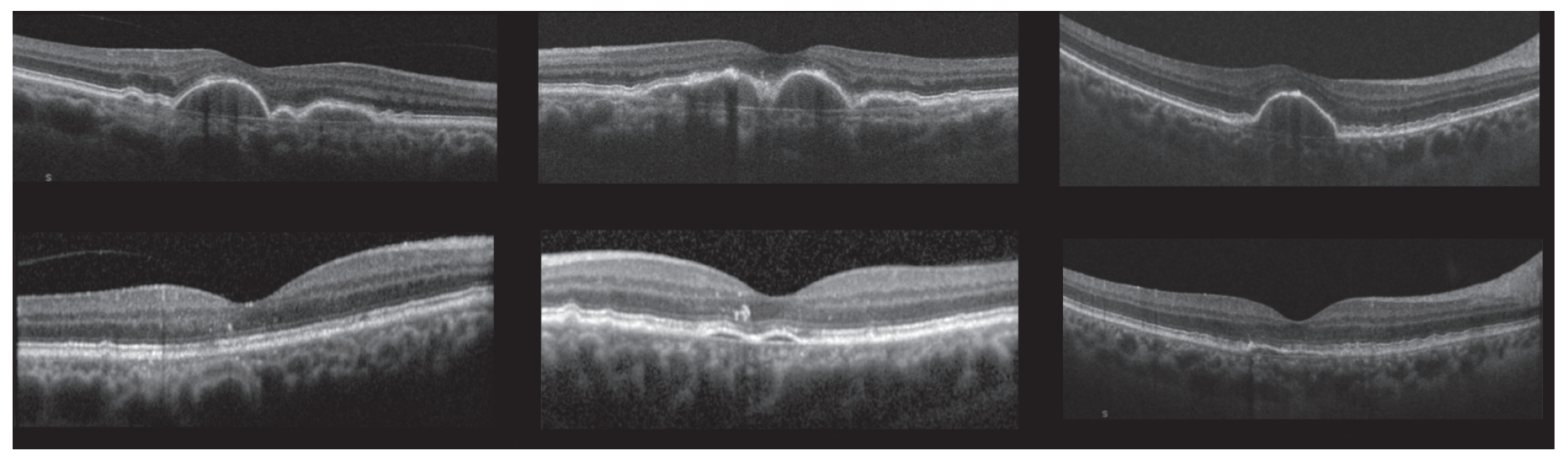

Adapted from Vavvas DG, Daniels AB, Kapsala ZG, et al., Regression of some high-risk features of age-related macular degeneration (AMD) in patients receiving intensive statin treatment, Ebiomedicine, 2016;5:198-203. Copyright 2016 by Vavvas GD, Daniels AB, Kapsala ZG, et al.

a given point it becomes pathogenic, leading to disease development. It is important to note that human histological/biochemical data on pathological inflammation or para-inflammation in AMD remain sparse. A study in 2015 showed involvement of CD163+ cells in the eyes of patients with AMD; $; 3$ another study found elevated vitreal granulocytemacrophage colony-stimulating factor (GM-CSF) and increased CD68+ choroidal macrophages. ${ }^{34}$ In a more recent study from 2017, complement factor 3-positive immune cells were observed in AMD specimens. ${ }^{35}$ With imperfect animal models, sparse human data, and the potential for parainflammation to also be protective in aging, it remains unclear how we should modulate the inflammatory response to obtain a therapeutic effect in patients with AMD. There is clearly a need for further investigation into the role of inflammation in the pathogenesis of AMD.

\section{Complement}

The discovery of the association with AMD of gene polymorphisms in the complement regulatory component, factor $\mathrm{H}(\mathrm{CFH})$ that regulates the alternative complement pathway was a seminal finding. Additional studies have implicated single-nucleotide polymorphisms (SNPS) in other complement genes including CFI, CFB, and CFD as risk alleles as well..$^{36-42}$

Klein et al., Haines et al., and Hageman et al. in 2005 identified CFH polymorphisms in AMD. All groups identified a tyrosine to histidine polymorphism in the region of $\mathrm{CFH}$ that binds heparin and $\mathrm{C}$-reactive protein. The odds ratio (OR) varied according to homozygosity and among the different studies, ranging from 2.46-7.4. Smoking was found to increase AMD risk related to $\mathrm{CHF}$ as smokers homozygous for the $\mathrm{CFH} Y 402 \mathrm{H}$ variant had an OR of 34 for late-stage AMD compared with non-smokers without the risk allele. ${ }^{43}$ It is important to note that these results suggest that up to a third of the US population 65 years or older without AMD (12.7 million people $)^{44}$ may have the most frequent at-risk haplotype for AMD without developing the disease.

Plasma levels of complement proteins have been shown to increase with age, ${ }^{45}$ but, it is postulated that patients with AMD have a stronger imbalance of complement activation and regulation, possibly leading to complement over-activity. Greater increases in complement protein plasma levels have been associated with advanced stages of AMD, leading to the hypothesis that complement activation may be correlated with disease progression as well. ${ }^{45,46}$ There is weak evidence that genetic polymorphisms in CHF associated with AMD may lead to over-activity of complement. Scholl et al. found that median plasma concentrations of CHF were not increased in patients with $\mathrm{AMD}^{47}$ whereas complement factor $\mathrm{D}$ (CFD) levels did, indicating that CFD may be a more promising target for AMD therapy than CHF. In these studies, the increased plasma concentrations of complement protein observed were wide-ranging and the ranges for different components of the complement system also varied greatly (Table 4). A significant increase of C3a was found in AMD patients, ranging from 4.6-87.2\%; C5a levels were found to range from $10.8-46.7 \% .{ }^{47-51}$ Scholl et al. found a significant increase in CFD levels by $32.6 \%$ compared to normal controls and no significant difference in CFH levels. ${ }^{47}$ However, Reynolds et al. did not find a significant difference of CFD levels between AMD patients and controls, but identified a significant decrease (7.4\%) in $\mathrm{CFH}$ plasma concentrations in patients with GA. ${ }^{48}$ Table 4 summarizes the data on systemic complement factor levels in AMD and controls. Please note the wide variability in ranges of these studies.

Histology of AMD eyes has demonstrated expression of many complement components in drusen. ${ }^{52,53}$ It should be noted, however, that antibody studies are tricky, and it is difficult to draw definitive conclusions from them because many antibodies are notoriously "dirty", as many bind non-specifically—especially in "sticky" drusenoid deposits. Mullins et al. demonstrated labeling of membrane attack complex (MAC) in Bruch's membrane and choriocapillaris with age and in AMD, concluding that choroidal endothelial cells are targeted by MAC leading to choroidal thinning in AMD. ${ }^{54}$ The immunofluorescence performed by this group shows extensive MAC-labeling throughout the choriocapillaris, targeting almost every choroidal endothelial cell. ${ }^{54}$ The widespread labeling of choriocapillaris (CC) endothelial cells with MAC without apparent massive and rapid loss of $C C$ in AMD suggest that this observed MAC labeling maybe an artifact or, as the authors speculate, the MAC labeling seen may result in as yet unproven sub-lytic deleterious effect and slow long-term deterioration of endothelial cell function.

Despite the evidence suggesting a role of the complement system in $\mathrm{AMD}$, trials targeting complement proteins in $\mathrm{AMD}$ have so far failed to 
Table 3: Genes involved in age-related macular degeneration pathogenesis

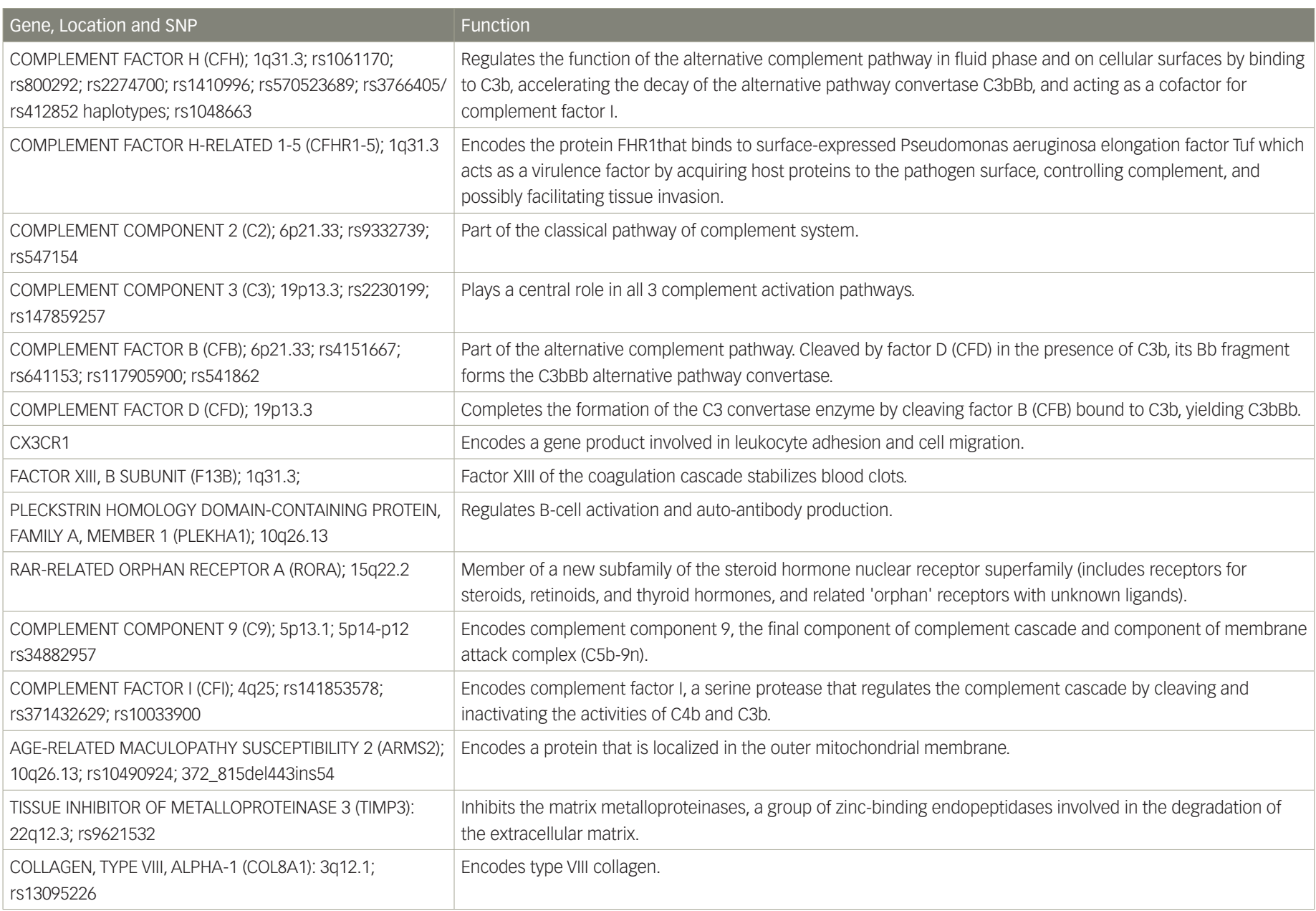

demonstrate efficacy. The anti-C5 antibody eculizumab (Soliris ${ }^{\circledast}$; Alexon Pharmaceuticals, Cheshire, CT, US) investigated in the COMPLETE study (NCT00935883), as well as by Filho et al., failed to show reduction in GA growth rate at 6 months, or reduction in drusen volume at 26 weeks of treatment. 55,56 A phase II/III trial of ARC1905 (Zimura; Ophthotech Corp., Princeton, NJ, US), an intravitreous anti-C5 aptamer is currently recruiting participants with GA (NCT02686658). ${ }^{57}$ More recently, the MAHALO phase II clinical trial (NCT01229215) investigated the safety and efficacy of lampalizumab—a complement factor D antibody_for the treatment of GA in monthly injected subjects and controls over 18 months. The study showed a trend to reduction in GA progression of $20 \%$, but was not significant..$^{58}$ Two phase III trials to investigate the safety and efficacy of monthly or 6-weekly injections of lampalizumab have completed recruiting participants (CHROMA, NCT02247479 and SPECTRI, NCT02247531). ${ }^{59,60}$ Results of the phase III study SPECTRI were recently announced and showed no efficacy. Similar negative results of CFD inhibition in AMD from the CHROMA study are expected in a few months.

A phase I trial for the intravitreal complement C3 inhibitor POT-4 in patients with neovascular AMD showed no safety concerns, however, a phase II trial has not been initiated as of yet (NCT00473928). ${ }^{61,62}$ Finally, two phase II clinical trials have investigated amyloid-beta antibodies for the treatment of GA (NCT01577381, NCT01342926). Amyloid-beta, a component of drusen, is believed to be an activator of complement, and is thought to play a role in AMD progression. Outcomes for these studies are not yet available. ${ }^{63-66}$

\section{NLRP3 inflammasome}

Another component of inflammation that has been proposed to play a role in AMD is the NACHT, LRR, and PYD domains-containing protein 3 (NLRP3) inflammasome. The NLRP3 inflammasome is a protein complex within immune cells and is part of innate immunity leading to activation and release of interleukin (IL)-1 $\beta$ and IL-18. In 2012, Tarallo et al. published that Alu RNA transcripts accumulated in RPE following loss of DICER1 expression primed and activated the NLRP3 inflammasome in RPE, leading to IL-1 $\beta$ and IL-18-mediated degeneration of RPE. ${ }^{67}$ However, in the same year Doyle et al. suggested that NLRP3 in infiltrating macrophages and microglia was activated by drusen and drusen components such as C1Q. This NLRP3 activation led to increased IL-18 levels, ultimately providing protection from neovascular AMD in rodent and primate models. ${ }^{68-70}$ More recent studies by our group suggest that inhibition of RPE NLRP3 is unlikely to be an effective approach in AMD (unpublished data).

\section{Aging and senescence}

Aging remains one of the biggest risks in AMD. Cell senescence is a biological change linked to aging and many age-related diseases. There are 
Table 4: Complement protein plasma concentrations in patients with age-related macular degeneration compared to normal controls

\begin{tabular}{|c|c|c|c|c|c|c|}
\hline $\begin{array}{l}\text { Complement } \\
\text { component }\end{array}$ & AMD type & $\begin{array}{l}\text { Blood levels in } \\
\text { controls (n) }\end{array}$ & $\begin{array}{l}\text { Blood Levels } \\
\text { in AMD (n) }\end{array}$ & difference $\%$ & $\mathrm{p}$ value & Study \\
\hline \multirow[t]{6}{*}{$\begin{array}{l}\mathrm{C} 3 \mathrm{a} \\
\mathrm{ng} / \mathrm{ml}\end{array}$} & early AMD & $\begin{array}{l}35.8 \\
(38)\end{array}$ & $\begin{array}{l}67.0 \\
(42)\end{array}$ & +87.2 & 0.02 & Sivaprasad et al. 2007 \\
\hline & $\begin{array}{l}\text { all types } \\
\text { (9 early, } 78 \mathrm{NV}, 25 \mathrm{GA} \text { ) }\end{array}$ & $\begin{array}{l}14.3 \\
(67)\end{array}$ & $\begin{array}{l}15.5 \\
(112)\end{array}$ & +8.4 & 0.03 & Scholl et al. 2008 \\
\hline & GA & $\begin{array}{l}1498 \\
(60)\end{array}$ & $\begin{array}{l}1567 \\
(58)\end{array}$ & +4.6 & 0.03 & Reynolds et al. 2009 \\
\hline & \multirow[t]{3}{*}{ NV } & $\begin{array}{l}35.8 \\
(38)\end{array}$ & $\begin{array}{l}68.3 \\
(42)\end{array}$ & +90.8 & 0.02 & Sivaprasad et al. 2007 \\
\hline & & $\begin{array}{l}1498 \\
(60)\end{array}$ & $\begin{array}{l}1647 \\
(62)\end{array}$ & +9.9 & 0.22 & Reynolds et al. 2009 \\
\hline & & $\begin{array}{l}11.95 \\
(43)\end{array}$ & $\begin{array}{l}14.65 \\
(96)\end{array}$ & +22.6 & $<0.001$ & Lechner et al. 2016 \\
\hline $\begin{array}{l}\mathrm{C} 4 \mathrm{a} \\
\mathrm{ng} / \mathrm{ml}\end{array}$ & NV & $\begin{array}{l}68.91 \\
(43)\end{array}$ & $\begin{array}{l}108.48 \\
(96)\end{array}$ & +57.4 & 0.005 & Lechner et al. 2016 \\
\hline \multirow[t]{5}{*}{$\begin{array}{l}\mathrm{C5a} \\
\mathrm{ng} / \mathrm{ml}\end{array}$} & $\begin{array}{l}\text { all types } \\
\text { (9 early, } 78 \mathrm{NV}, 25 \mathrm{GA} \text { ) }\end{array}$ & $\begin{array}{l}1.67 \\
(67)\end{array}$ & $\begin{array}{l}1.85 \\
(112)\end{array}$ & +10.8 & 0.04 & Scholl et al. 2008 \\
\hline & GA & $\begin{array}{l}14 \\
(60)\end{array}$ & $\begin{array}{l}17 \\
(58)\end{array}$ & +21.4 & 0.02 & Reynolds et al. 2009 \\
\hline & \multirow[t]{3}{*}{ NV } & $\begin{array}{l}14 \\
(60)\end{array}$ & $\begin{array}{l}16 \\
(62)\end{array}$ & +14.3 & 0.09 & Reynolds et al. 2009 \\
\hline & & $\begin{array}{l}150 \\
(150)\end{array}$ & $\begin{array}{l}220 \\
(197)\end{array}$ & +46.7 & $<0.001$ & Smailhodzic et al. 2012 \\
\hline & & $\begin{array}{l}8.34 \\
(43)\end{array}$ & $\begin{array}{r}9.43 \\
(96)\end{array}$ & +13.1 & 0.049 & Lechner et al. 2016 \\
\hline \multirow[t]{4}{*}{$\begin{array}{l}\text { CFB } \\
\mu g / m l\end{array}$} & $\begin{array}{l}\text { all types } \\
\text { (9 early, } 78 \mathrm{NV}, 25 \mathrm{GA} \text { ) }\end{array}$ & $\begin{array}{l}642 \\
(67)\end{array}$ & $\begin{array}{l}803 \\
(112)\end{array}$ & +25.1 & 0.02 & Scholl et al. 2008 \\
\hline & GA & $\begin{array}{l}228 \\
(60)\end{array}$ & $\begin{array}{l}249 \\
(58)\end{array}$ & +9.2 & 0.21 & Reynolds et al. 2009 \\
\hline & \multirow[t]{2}{*}{ NV } & $\begin{array}{l}228 \\
(60)\end{array}$ & $\begin{array}{l}251 \\
(62)\end{array}$ & +10.1 & 0.19 & Reynolds et al. 2009 \\
\hline & & $\begin{array}{l}15.9 \mathrm{mg} \% \\
(150)\end{array}$ & $\begin{array}{l}16.9 \mathrm{mg} \% \\
(197)\end{array}$ & +6.3 & $<0.001$ & Smailhodzic et al. 2012 \\
\hline \multirow[t]{3}{*}{$\begin{array}{l}\text { CFD } \\
\mu \mathrm{g} / \mathrm{ml}\end{array}$} & $\begin{array}{l}\text { all types } \\
\text { (9 early, } 78 \mathrm{NV}, 25 \mathrm{GA} \text { ) }\end{array}$ & $\begin{array}{l}0.95 \\
(67)\end{array}$ & $\begin{array}{l}1.26 \\
(112)\end{array}$ & +32.6 & $<0.001$ & Scholl et al. 2008 \\
\hline & GA & $\begin{array}{l}3.2 \\
(60)\end{array}$ & $\begin{array}{l}3.4 \\
(58)\end{array}$ & +6.3 & 0.42 & Reynolds et al. 2009 \\
\hline & NV & $\begin{array}{l}3.2 \\
(60)\end{array}$ & $\begin{array}{l}3.5 \\
(62)\end{array}$ & +9.4 & 0.25 & Reynolds et al. 2009 \\
\hline \multirow[t]{4}{*}{$\begin{array}{l}\mathrm{CFH} \\
\mu \mathrm{g} / \mathrm{ml}\end{array}$} & $\begin{array}{l}\text { all types } \\
\text { (9 early, } 78 \mathrm{NV}, 25 \mathrm{GA} \text { ) }\end{array}$ & $\begin{array}{l}515 \\
(67)\end{array}$ & $\begin{array}{l}546 \\
(112)\end{array}$ & +6 & 0.21 & Scholl et al. 2008 \\
\hline & GA & $\begin{array}{l}312 \\
(60)\end{array}$ & $\begin{array}{l}289 \\
(58)\end{array}$ & -7.4 & 0.008 & Reynolds et al. 2009 \\
\hline & \multirow[t]{2}{*}{ NV } & $\begin{array}{l}312 \\
(60)\end{array}$ & $\begin{array}{l}295 \\
(62)\end{array}$ & -5.4 & 0.06 & Reynolds et al. 2009 \\
\hline & & $\begin{array}{l}24.5 \mathrm{mg} \% \\
(150)\end{array}$ & $\begin{array}{l}24.9 \mathrm{mg} \% \\
(197)\end{array}$ & +1.6 & 0.654 & Smailhodzic et al. 2012 \\
\hline
\end{tabular}

$A M D=$ age-related macular degeneration; $C F B=$ complement factor $B ; C F H=$ complement factor $H ; G A=$ geographic atrophy; $N V=$ neovascular.

multiple alterations that happen in the senescent cell, including shortening of telomeres, activation of the DNA damage response (DDR) through the ataxia telangiectasia mutated (ATM)-p53-p21 axis, and the p16Ink4a protein ( $\mathrm{p} 16)$ leading to an activation state of retinoblastoma $(\mathrm{Rb})$ protein. senescent cells are also known to be marked by an elevation of lysosomal- $\beta$-galactosidase (SA- $\beta$-GAL) that has served as a rather easy and specific marker of senescent cells. ${ }^{71-75}$

Cellular senescence is thought to cause tissue repair impairment through the production of inflammatory senescence-associated secretory 
phenotype (SASP)—pro-inflammatory and matrix degrading molecules that are mediated largely by NF-KB and p38 MAPK signaling. ${ }^{76,77}$ Although senescence is associated with some harmful effects, not all senescent cells are thought to be detrimental. Short-lived cellular senescence may help in morphogenesis, wound repair, and tumor suppression. ${ }^{78-81}$ Senescent cells may also be effectively cleared by the immune cells that are called in by the SASP components. ${ }^{82,83}$ However, chronic senescent cells that are not cleared are thought to be harmful and contribute to tissue dysfunction.

It is rather surprising that cellular senescence has not been systematically or extensively studied in AMD. ${ }^{84}$ RPE cells show senescence in vitro, ${ }^{85-89}$ and senescence-prone mouse strain 8 has shown photoreceptor loss and increased p16 expression in RPE cells. ${ }^{90}$ To date, there appears to be a lack of cell senescence data in humans, and there is only one non-human primate study which detected senescence markers in the RPE of aged monkeys. ${ }^{75}$

In aging and senescence, not only do lysosomal hydrolases like SA- $\beta$-GAL change, but the lysosomes themselves, as well as many of their functions, are altered. ${ }^{91}$ Lysosome-associated membrane protein-2 (LAMP-2) is a lysosomal protein essential for many functions including autophagy, and its expression is known to decline with age in the body. ${ }^{92}$ Systemic mutation of this protein leads to Danon's disease, characterized by the classic triad of cardiomyopathy, skeletal myopathy, and mental retardation..$^{93}$ Importantly, Danon's disease also includes progressive retinal degeneration. ${ }^{94-96}$ In experimental systems, impeded phagocytic degradation of photoreceptor outer segments, compromised lysosomal degradation, and increased Iysosomal exocytosis all contributed to the formation of sub-RPE deposits in Lamp2-deficient RPE cells. ${ }^{97}$ Notably, Lamp-2-deficient mice recapitulate several classical features observed in AMD such as extensive sub-RPE drusenoid deposits, and progressive RPE cell loss followed by photoreceptor cell loss and atrophy. ${ }^{97}$

Another feature of aging is impairment of clearing damaged DNA. It has been shown both in human AMD specimens and in vitro experiments that there is an increase in damaged mitochondrial DNA (mtDNA) in the RPE of patients with $A M D$, leading to para-inflammation. ${ }^{98-103}$ Similar findings have been observed with damaged genomic DNA. ${ }^{104}$ What contributes to the damaged DNA and whether it is causative or a feed-forward epiphenomenon need further investigation.

Studies on longevity regulator proteins have focused primarily on silent information regulator T1 (SIRT1), ${ }^{105,106}$ and, to a lesser degree, AMPdependent kinase (AMPK). ${ }^{107}$ SIRT1 is a member of NAD+dependent protein deacetylases responsible for controlling a wide variety of signaling and transcription factors. ${ }^{105,106}$ AMPK is the energy sensor of the cellresponding to the AMP/ATP ratio, suppressing anabolic pathways, and stimulating energy producing processes. ${ }^{107}$ Caloric restriction is one of the most potent longevity stimuli and is known to increase SIRT1 expression, as well as AMPK activity. ${ }^{107-114}$ Relatively little is known about the role of SIRT1 and AMPK in AMD. However, one study suggested that genetic variations of SIRT1 could be implicated in the pathophysiology of AMD in the chinese Han population. ${ }^{115}$ Another study indicated that lower expressions of SIRT1 and PGC1 $\alpha$ were observed in IPSC-derived RPE cells from patients with AMD. ${ }^{116}$ Even less data exist for AMPK and AMD - a few reports suggested AMPK and mechanistic target of rapamycin (MTOR) as potential therapeutic targets in AMD, ${ }^{117,118}$ while in vitro experiments suggested a protective effect for AMPK activation on RPE cells and downregulation of complement factor
B (unpublished data, Eun Jee Chung et al.). ${ }^{119}$ Work from our group has shown that aging changes in photoreceptor connectivity are associated with reduction of AMPK in mice. Pharmacologic activation through Metformin or caloric restriction can reverse these aging changes. ${ }^{120}$ Further investigation is needed to identify therapeutic targets for AMD that will have the ability to reverse senescence and stimulate longevity.

\section{Neovascular age-related macular degeneration Anti-vascular endothelial growth factor therapy and long-term results}

Vascular endothelial growth factor (VEGF)—first identified as a vasopermeability factor and initiator of angiogenesis due to hypoxia-is the key angiogenic factor in neovascular AMD. Anti-VEGF treatment for eye diseases has been one of the greatest success stories in modern medicine, and has resulted in preserving and/or improving vision for millions of people. Although more than $80 \%$ of patients have "dry" retinas with antiVEGF monotherapy, there is an incomplete gain in visual function. ${ }^{121-125}$ Over longer periods of time, there is loss of the vision gains occurring within the first 2 years of anti-VEGF treatment. ${ }^{122,126-128}$ Part of the reason for the loss of visual gains in the long-term is likely due to under-treatment in the "real" world. 129,130 However, as these retinas are virtually "dry" with little to no intraretinal fluid present, this suggests that something else is responsible for the decline in visual function observed in these patients. Even when the neovascular process is controlled, the underlying degenerative process continues with a progression of GA in patients with neovascular AMD. This suggests an important role for neuroprotection, to be discussed later. The progression of atrophic changes may be furthered by decreased perfusion and resulting ischemia, as the regression of CNV with anti-VEGF may eliminate the only remaining blood supply for the outer retina. ${ }^{131}$ Another explanation for this phenomenon could be the that the neurotrophic effect of VEGF is blocked by anti-VEGF treatment; however, there is little clinical evidence for this. ${ }^{132}$

It is also important to remember the considerable burden of monthly anti-VEGF injections on patients, their support network, and providers. ${ }^{133}$ Improving treatment for neovascular AMD should therefore both: (1) include a better outcome in terms of improved visual acuity, and (2) reduce the number of injections needed for effective treatment. Some believe that targeting another angiogenic factor could be helpful. To date, these approaches have been unsuccessful. To decrease the number of injections, investigators have studied ways to extend the duration of anti-VEGF effect through long-term sustained release of macromolecules, with no success. The lack of success in finding methods for long-term sustained release may be due in part to the large size of the molecules (50,000-150,000 Da), limiting the number of molecules that can effectively be packed within a usable volume. With a smaller fragment (25,000 Da) of anti-VEGF antibody called RTH258 (brolucizumab), Novartis has been able to increase the injection amount to $6 \mathrm{mg}$ (equivalent in molar dose to $12 \mathrm{mg}$ of ranibizumab), successfully extending the dosing frequency to 12 -week intervals. ${ }^{134-137}$

Another approach to circumvent these physical limitations is to use a refillable reservoir that can contain material for 6 months. This approach is championed by Genentech after it acquired ForSight Vision. The two companies have been collaborating for several years to develop the refillable rigid port delivery system (RPDS). The RPDS is an intravitreal implant that is placed surgically through a scleral incision that, in theory, can be refilled by a physician using proprietary refill needle in the office. Although it appears 
that it can contain enough material for slow release over 4-6 months, it has yet to show that it can be refilled successfully several times. The clinical trial investigating this refillable device (LADDER; NCT02510794) is still active. ${ }^{138}$ Additionally, hydrogels as sustained-release deposits for both small and large molecules are being investigated by Regeneron with Ocular Therapeutix, but these studies are still in preclinical stage. ${ }^{139}$

\section{Platelet-derived growth factor}

Platelet-derived growth factor (PDGF), a dimeric glycoprotein, is critical for pericyte survival, recruitment, and maturation. PDGF-receptor-beta (PDGFB) deficiency has been shown to result in microvascular pericyte Ioss, the development of capillary microaneurysms leading to proliferative retinopathy, and the inability of sprouting capillary endothelial cells to attract PDGFB-positive pericyte progenitor cells. ${ }^{140,141}$ Pericytes protect endothelial cells from VEGF inhibition; therefore, pericyte loss in the neovascular complex was believed to act synergistically with anti-VEGF therapy, leading to an increased endothelial cell response to anti-VEGF treatment.

Despite the early excitement about the potential of anti-VEGF and antiPDGF combination therapy for neovascular AMD, two large clinical trials failed to meet the optimism created by successful preliminary studies. The failure of the PDGF trials was not entirely surprising as there were several hints suggesting that they may be less than successful. First, antiVEGF monotherapy is sufficient to "dry" the macula in the clear majority of patients. Thus, it is difficult to conceive additive effects with an adjuvant therapy that also targets angiogenesis. Second, targeting of pericytes in neovascularization may not be desirable, since pericytes are needed for vessel maturation and therefore decreased vascular leakage. ${ }^{142}$ Third, evidence suggested that PDGF-BB and VEGF do not synergize in all models of ischemia-related angiogenesis; PDGF may synergize with FGF instead. ${ }^{140}$ Finally, the role of PDGF expression in the outer nuclear layer of the macula of patients with AMD is still undetermined and other off-target effects of PDGF inhibition remain to be elucidated. ${ }^{140}$

\section{Angiopoietin-TIE Pathway}

Another major player in the process of angiogenesis, is angiopoietin (ANG)-1, a glycoprotein that binds to tyrosine kinase receptor TIE2. TIE2 is expressed on endothelial cells as well as early hematopoietic cells. ${ }^{140}$ The ANG/TIE2 pathway is involved in maintaining vascular integrity and stability. ${ }^{143}$ Knockout of ANG-1 or TIE2 leads to embryonic lethality, with failure of smooth-muscle and pericyte precursor recruitment. ANG-2 is a competitive antagonist of ANG-1 for the TIE2 receptor. Binding of ANG-2 to TIE2 does not lead to phosphorylation of the receptor. ${ }^{144}$ Overexpression of ANG-2 in mice leads to disruption of blood vessel formation and gives a phenotype similar to that of ANG-1 deficient mice. ${ }^{144}$ It is thought that ANG-2 mediates endothelial cell survival, increasing their responsiveness to VEGFenhancing neovascularization. ${ }^{144}$ It was also noted by the authors of this study that ANG-2 in fibroblasts could activate TIE2 receptors when VEGF is absent, and this ANG-2 stimulation may lead to vessel regression. ${ }^{144}$ In the corneal micropocket assay, neither ANG-1 or ANG-2 alone could lead to neovascularization, however, they were able to augment VEGF effects, with ANG-2 being more potent than ANG-1. In cases of VEGF-inhibition, ANG-2 binding resulted in apoptosis. ${ }^{140}$

There has been a lot of interest in exploring angiopoetin as a therapeutic target for neovascular AMD and other retinal vascular diseases. Elevated levels of ANG-2 (43 versus $9 \mathrm{pg} / \mathrm{L}$ ) were found in the aqueous humor of patients with neovascular $\mathrm{AMD}^{145}$ and a small study from Hong Kong has shown some suggested associations between ANG-2 SNPs and neovascular AMD, particularly polypoidal. ${ }^{146}$ Otani et al. showed that surgically excised CNV stained positive for ANG-1 and ANG-2 with increased ANG-2 immunoreactivity in the highly vascularized regions of CNV - similar to the staining pattern of VEGF. ${ }^{147}$ Heras et al. also detected variable amounts of VEGF, ANG-1, and ANG-2 in surgically excised CNV membranes; TIE-2 and VEGF receptor (VEGFR) were not detectable in their study. ${ }^{148}$

Several preclinical studies suggest that direct or indirect activation of the ANG-1 system diminishes CNV and VEGF-induced leakage. ${ }^{149-151,143}$ A 12-week phase Ila clinical trial of AKB-9778 (an inhibitor of vascular endothelial protein tyrosine phosphatase, and indirect activator of ANG1/TIE2) showed that patients with diabetic macular edema receiving a combination therapy of ranibizumab with subcutaneous AKB-9778 had significantly more reduction in mean macular thickness at 12 weeks compared with the ranibizumab monotherapy group. However, there was no better visual acuity than with monotherapy alone (NCT02050828). ${ }^{152}$ A phase IIb clinical trial of AKB-9778 is currently recruiting patients with non-proliferative diabetic retinopathy (TIME-2b, NCT03197870). In the field of oncology, a phase II study targeting angiosarcoma using antrebananib to block both ANG-1 and ANG-2 failed to show efficacy. ${ }^{153} \mathrm{~A}$ new bispecific crossed monoclonal antibody (crossMAb) has been developed by Roche targeting both VEGF and ANG-2, and may be more efficacious than antiVEGF alone in the non-human primate model of CNV. ${ }^{154}$

In summary, ANG-2 is important for vascular physiology and there is a potential for synergistic effects in combination with anti-VEGF in retinal diseases. However, for the reasons alluded to above, combination antiangiogenic therapy in neovascular AMD may not be effective. Anti-VEGF treatment alone usually very effectively "dries" the retina in patients with neovascular AMD, leaving little room for improvement. In addition, while most studies suggest advantages of blocking ANG-2 in neovascular diseases, some basic science research suggests that ANG-2 may have opposing roles in neovascularization depending on the environmental context. It may be that ANG-2 blockade is more valuable in diseases with more typical inflammation and in true anti-VEGF non-responders, such as one finds in diabetic retinopathy.

As such, future treatments targeting the neovessels in neovascular AMD should be aimed at increasing the dosing interval and decreasing the need for frequent injections, as opposed to increasing the anti-angiogenic effect. It is also important to consider increased anti-angiogenesis therapy aimed at the regression of CNV may eliminate the only remaining blood supply to the outer retina, leading to progression of atrophy and worsening of the disease.

\section{Future treatments-neuroprotection}

ongoing neurodegeneration leads to GA. Given that AMD is a multifactorial polygenetic disease, our group has used many animal models to investigate commonalities in cell death processes and the reasons why prior approaches on inhibiting apoptosis have failed. Using the separation of photoreceptors from the RPE as a model of cell death, we and others have found evidence of caspase-mediated apoptosis as well as elevation of upstream death signals such as TNF and FAS ligand (FasL). ${ }^{155-167}$ However, blocking caspases did not lead to prevention of cell death, ${ }^{167,168}$ leading us to investigate other forms of cell death. Through morphological studies, we 
Figure 3: Schematic of molecular pathways involved in death signaling

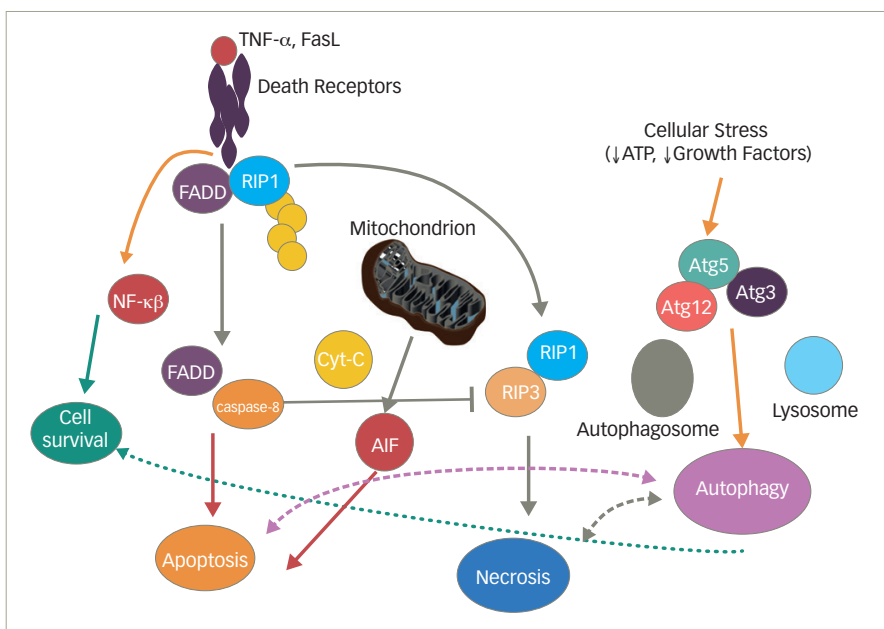

Upstream death ligands (tumor necrosis factor and FasL) bind to their corresponding receptors and initiate downstream cascades that interact and cross-talk. Cell death can be initiated by intracellular stressors as well. Note that cross-talk between death signaling and pro-survival and pro-inflammatory mechanisms occurs through Nf-k $\beta$. Autophagy is activated under stress and helps initially to promote cell survival. Prolonged activation of autophagy leads to cell loss.

have known since the 1970s that at least three different forms of cell death exist. ${ }^{169}$ The first one (Type I) was characterized by cell condensation and fragmentation and is now known as caspase-mediated apoptotic cell death. The second type (Type II) was characterized by the presence of numerous double membrane vacuoles/structures and is now known as autophagymediated cell death. The third form of cell death (Type III), necrosis, was characterized by cell swelling, membrane blebbing, vacuolization, and cell rupture-for years it was thought to be unregulated and haphazard. However, more recent studies have indicated that the Type III modality of cell death is also regulated by a set of protein kinases called receptorinteracting protein kinases or RIPK. ${ }^{170,171}$

In addition to evidence for caspase-mediated cell death, we examined evidence of RIPK-mediated necrosis in photoreceptor cell death. Indeed, using the retinal detachment model, we found upregulation of expression and phosphorylation of RIPK along with activation of caspases (Figure 3). ${ }^{160,167,172,173}$ When we tried to inhibit RIPK or caspases in isolation, no major effect on photoreceptor loss was observed. ${ }^{167}$ In contrast, combined treatment led to significant rescue. ${ }^{167}$ In further investigations using morphologic assessment via electron microscopy, we observed that caspase inhibition alone led to decreased apoptotic cell death; however, it increased necrotic cell death, thus leaving the overall level of cell death unaltered. It was only when both cell death pathways were blocked that reduced overall cell death was observed (Figure 4). ${ }^{167}$ Thus, we can conclude that there are common cell death pathways that are redundant and complimentary to each other. Cells have alternative death pathways to caspase-mediated apoptosis that are mediated through RIPK activation. Blocking only one pathway is not sufficient and in order to prevent photoreceptor cell death, it likely is necessary to block both apoptotic and necrotic pathways.

Our findings from the photoreceptor/RPE separation model of cell death were then further explored in other models of AMD such as the dsRNA model of retinal degeneration. Using that model of photoreceptor and RPE
Figure 4: Schematic demonstrating proposed integration of cell death signaling in retinal degenerations

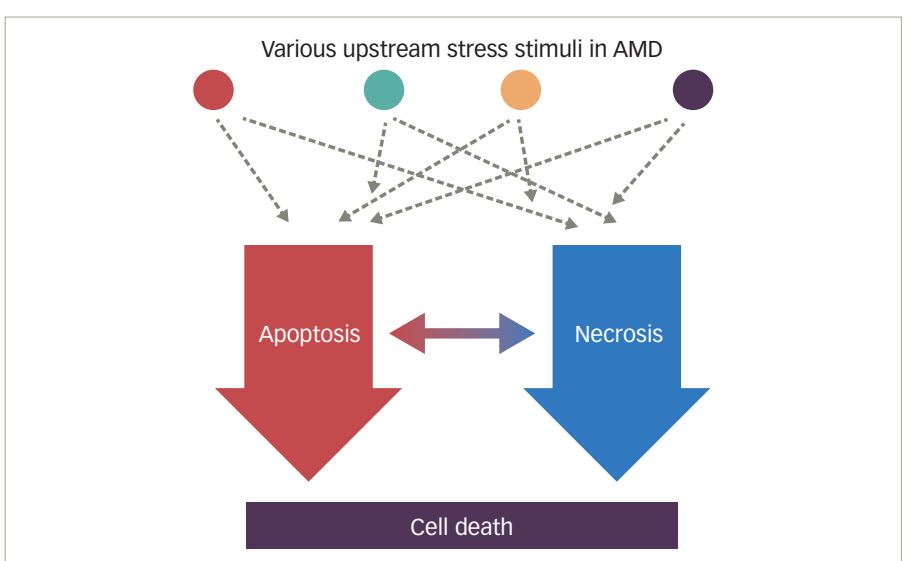

Age-related macular degeneration (AMD) is multifactorial in its etiology. Various upstream stressors (both from within the cell and outside the cell) activate multiple pathways that they lead eventually to cell death. Cell death is mediated in many instances through apoptosis and necrosis. This dual pathway is a redundant and complimentary system that cross-talks to each other to effectively lead to cell death. Successful neuroprotection in $A M D$ and other degenerations would require combination therapies that can target both pathways.

cell death, we found that the predominant cell death modality may be different between photoreceptors and RPE. Photoreceptors appeared to die predominantly through apoptosis, whereas RPE cells exhibited mainly necrotic features. ${ }^{174}$ Similar to our prior work, inhibition of caspases or RIPK in isolation was less effective than combination in preventing overall photoreceptor and RPE cell death after dsRNA-induced injury. The significant role of RIPK in RPE cell death was also observed in an in vitro model of RPE toxicity induced by tamoxifen. Pan-caspase inhibition failed to protect RPE cells, whereas addition of RIPK inhibitors, alone or in combination, led to significant RPE survival. ${ }^{175}$

In contrast to apoptosis, regulated necrosis is more inflammatory. We recently found evidence of increased inflammasome activation in patients with photoreceptor injury due to retinal detachment. ${ }^{172}$ Using an animal model of retinal detachment, we showed that the primary source of inflammasome activation and production of $\mathrm{IL}-1 \beta$ was a partially RIPKdependent pathway from the infiltrating macrophages rather than the injured retinal cells. ${ }^{172}$ Additionally, we found that infiltrating macrophages (and maybe resident microglia) expressed FasL that was responsible for increased neuronal cell death. In contrast, soluble FasL was found to be neuroprotective. ${ }^{160}$

Thus, past neuroprotection strategies may have failed in part because of the focus on monotherapy. With the recognized redundancy of cell death pathways, combination therapy to block both pathways may be more effective (Figure 4). Neuroprotective strategies based on the above findings may apply to both dry AMD and wet AMD. Adjuvant neuroprotective therapy, along with anti-VEGF treatment, may prevent photoreceptor cell death in neovascular AMD, possibly leading to improvement in both short- and longterm vision outcomes. Furthermore, if successful, this type of combination therapy may also provide a broad-based, long-term treatment approach for a variety of retinal disorders.

It should be noted that evidence of specific end-stage cell death processes in human AMD specimens is sparse. This is inherently difficult since only 
a very limited number of cells are in the process of cell death at any given time point due to the slow process of the disease. As an example: assuming RPE cell death accounts for the observed GA growth rates of $1.85 \mathrm{~mm}^{2} /$ year, and knowing that macular RPE cell density is about 5,000 cells $/ \mathrm{mm}^{2},{ }^{176,177}$ we can conclude that just over 9,200 cells are dying per year. Using these calculations, the rate of cell death would be only 25 cells dying at any given day or approximately one cell dying per hour. As such, detecting end-point death signals in autopsy specimens is a tall order in the analysis of human AMD specimens.

\section{Biomarkers}

Identification of patients with AMD in earlier stages of the disease and prediction of individual progression rates will be of paramount importance for successful management of the disease. Previous attempts to identify serum biomarkers (C-reactive protein, homocysteine, and lipids) to identify patients with $\mathrm{AMD}$ and that correlate with disease progression yielded inconsistent data., ${ }^{8,78-180}$ More recently, researchers have looked into more systematic and unbiased approaches of finding biomarkers through metabolomics. Metabolomics is the study of all the metabolites (metabolome), the small molecule "fingerprints" of cellular processes. While genomic analysis gives us a snapshot of DNA code variation, and proteomics the set of gene products being produced in the cell, metabolomics enables us to study the relationship between genotype and phenotype, as well as the environment including nutrition and commensal organisms. It has been used to determine biofluid (blood and urine) marker profiles for several diseases, including cancer and Alzheimer's disease, and may provide an integrated biomarker signal for AMD.

In a recent metabolomics study at Massachusetts Eye and Ear, patients with $\mathrm{AMD}$ and without vitreoretinal disease (age $>50$ years) were recruited prospectively, examined, imaged, and a fasting blood sample was collected for metabolomics analysis. ${ }^{1{ }^{11,182}}$ Study results revealed that, after controlling for age, gender, body mass index, and smoking status, 87 metabolites were significantly associated with AMD. Most of these metabolites $(82.8 \%, n=72)$ belonged to the lipid super-pathway, particularly glycerophospholipids. Of the different metabolites between control and AMD patients, over half (48 metabolites) also differed significantly across AMD severity stages. Consistently, in patients with AMD versus control patients, and among the various stages of AMD, the vast majority of the identified metabolites were involved in lipid metabolism. These results led to further support for the importance of lipid metabolism, specifically glycerophospholipid metabolism, in AMD and suggest that metabolomic profiling is a potentially powerful tool to identify $A M D$, and to provide prognostic information and precise treatment.

\section{Future advances in treatment}

The lessons we learned from our successes in the development of therapies for neovascular AMD is that effective therapeutics arise either from understanding the pathogenesis of the disease or at least the key components of shared processes of complex multifactorial diseases. For example, despite the different causes of neovascularization, it is the same molecule-VEGF-that drives the process of newvessel formation. This latter understanding was crucial in leading not only to the success in treatment of neovascular AMD, but also to other retinal diseases. Understanding of common and shared pathogenetic processes in photoreceptor and RPE degeneration will be needed before we can be successful in generating the next generation of therapies in non-neovascular "dry" AMD. This can be achieved with better classification, better disease biomarkers, and improved basic science understanding of cell death machinery. There is no doubt that it is a matter of time before success arrives upon us. $\square$
1. Wong WL, Su X, Li X et al., Global prevalence of age-related macular degeneration and disease burden projection for 2020 and 2040: a systematic review and meta-analysis, Lancet Glob Health, 2014;2:e106-16.

2. Kramer M, Miller JW, Michaud N, et al., Liposomal benzoporphyrin derivative verteporfin photodynamic therapy. Selective treatment of choroidal neovascularization in monkeys, Ophthalmology, 1996;103:427-38.

3. Krzystolik MG, Afshari MA, Adamis AP, et al., Prevention of experimental choroidal neovascularization with intravitreal anti-vascular endothelial growth factor antibody fragment, Arch, Ophthalmol Chic III 1960, 2002;120:338-46.

4. Age-Related Eye Disease Study Research Group, Risk factors associated with age-related macular degeneration, A case-control study in the age-related eye disease study: AgeRelated Eye Disease Study Report Number 3, Ophthalmology, 2000;107;2224-32

5. Jager RD, Mieler WF, Miller JW, Age-related macular degeneration, NEng/ J Med, 2008:358:2606-17.

6. Ferris $\mathrm{FL}$, Wilkinson $\mathrm{CP}$, Bird A, et al., Clinical classification of agerelated macular degeneration, Ophthalmology, 2013;120:844-51

7. Wang L, Clark ME, Crossman DK, et al., Abundant lipid and protein components of drusen, PloS One, 2010;5:e10329.

8. Wang $Y$, Wang $M$, Zhang $X$, et al., The Association between the Lipids Levels in Blood and Risk of Age-Related Macular Degeneration, Nutrients, 2016;8:pii: E663.

9. Yip JLY, Khawaja AP, Chan MP, et al., Cross Sectional and Longitudinal Associations between Cardiovascular Risk Factors and Age Related Macular Degeneration in the EPIC-Norfolk Eye Study, PloS One, 2015;10:e0132565

10. Tan JSL, Mitchell P, Smith W, Wang JJ, Cardiovascular risk factors and the long-term incidence of age-related macular degeneration: the Blue Mountains Eye Study, Ophthalmology, 2007:114:1143-50

11. Erke MG, Bertelsen G, Peto T, et al., Cardiovascular risk factors associated with age-related macular degeneration: the Tromsø Study, Acta Ophthalmol (Copenh), 2014;92:662-9.

12. Vassilev ZP, Ruigómez A, Soriano-Gabarró M, García Rodríguez LA, Diabetes, cardiovascular morbidity, and risk of age-related macular degeneration in a primary care population, Invest Ophthalmol Vis Sci, 2015;56:1585-92.

13. Armstrong RA, Mousavi M, Overview of Risk Factors for AgeRelated Macular Degeneration (AMD), J Stem Cells, 2015;10:171-91.
14. Lee J, Zeng J, Hughes G, et al., Association of LIPC and advanced age-related macular degeneration, Eye Lond Engl, 2013;27:26570; quiz 271

15. Yu Y, Reynolds R, Fagerness J, et al., Association of variants in the LIPC and ABCA1 genes with intermediate and large drusen and advanced age-related macular degeneration, Invest Ophthalmol Vis Sci, 2011; 52:4663-70.

16. Merle BMJ, Maubaret C, Korobelnik JF, et al., Association of HDLrelated loci with age-related macular degeneration and plasma Iutein and zeaxanthin: the Alienor study, PloS One, 2013;8:e79848.

17. Curcio CA, Johnson M, Rudolf M, Huang J-D, The oil spill in ageing Bruch membrane, Br J Ophthalmol, 2011;95:1638-45.

18. VanderBeek BL, Zacks DN, Talwar N, et al., Role of Statins in the Development and Progression of Age-Related Macular Degeneration, Retina Phila Pa, 2013;33:414-22.

19. Klein R, Myers CE, Buitendijk GH, et al., Lipids, lipid genes, and incident age-related macular degeneration: the three continen age-related macular degeneration consortium, Am J Ophthalmol, 2014:158:513-524.e3.

20. Guymer RH, Baird PN, Varsamidis M, et al., Proof of concept, randomized, placebo-controlled study of the effect of simvastatin on the course of age-related macular degeneration, Plos One, 2013;8:e83759.

21. Gehlbach P, Li T, Hatef E, Statins for age-related macular degeneration, Cochrane Database Syst Rev, 2016;CD006927.

22. Cannon $\mathrm{CP}$, Braunwald $\mathrm{E}, \mathrm{McCabe} \mathrm{CH}$, et al., Intensive versus moderate lipid lowering with statins after acute coronary syndromes, Eng/ J Med, 2004;350:1495-504.

23. Pitt B, Waters D, Brown WV, et al., Aggressive lipid-lowering therapy compared with angioplasty in stable coronary artery disease. Atorvastatin versus Revascularization Treatment Investigators, N Engl J Med, 1999;341:70-76.

24. Khush K K, Waters D, Lessons from the PROVE-IT trial. Higher dose of potent statin better for high-risk patients, Cleve Clin J Med, 2004;71:609-16

25. Nissen SE, Effect of intensive lipid lowering on progression of coronary atherosclerosis: evidence for an early benefit from the Reversal of Atherosclerosis with Aggressive Lipid Lowering (REVERSAL) trial, Am I Cardiol, 2005;96:61F-68F.

26. Nissen SE, Tuzcu EM, Schoenhagen P, et al., Effect of intensive compared with moderate lipid-lowering therapy on progression of coronary atherosclerosis: a randomized controlled trial, JAMA 2004;291:1071-80.
27. Nissen SE, Nicholls SJ, Sipahi I, et al., Effect of very high-intensity statin therapy on regression of coronary atherosclerosis: the ASTEROID trial, JAMA, 2006;295:1556-65.

28. Yu C, Zhang Q, Lam L, et al., Comparison of intensive and lowdose atorvastatin therapy in the reduction of carotid intimalmedial thickness in patients with coronary heart disease, Heart, 2007;93:933-9.

29. Kramer CM, Mani V, Fayad ZA, MR Imaging-Verified Plaque Delipidation With Lipid-Lowering Therapy, JACC CardiovasC Imaging, 2011;4:987-9.

30. Zhao X-Q, Dong L, Hatsukami T, et al., MR Imaging of Carotid Plaque Composition During Lipid-Lowering Therapy, JACC Cardiovasc Imaging, 2011;4:977-86.

31. Vavas DG, Daniels AB, Kapsala ZG, et al., Regression of Some High-risk Features of Age-related Macular Degeneration (AMD) in Patients Receiving Intensive Statin Treatment, EBioMedicine 2016;5:198-203.

32. Medzhitov R, Origin and physiological roles of inflammation, Nature 2008:454:428-35.

33. Lad EM, Cousins SW, Van Arnam JS, Proia AD, Abundance of infiltrating CD163+ cells in the retina of postmortem eyes with dry and neovascular age-related macular degeneration, Graefes Arch Clin Exp Ophthalmol, 2015;253:1941-5

34. Wang JCC, Cao S, Wang A, et al., CFH Y402H polymorphism is associated with elevated vitreal GM-CSF and choroidal macrophages in the postmortem human eye, Mol Vis, 2015:21:264-72.

35. Natoli R, Fernando N, Jiao H, et al., Retinal Macrophages Synthesize C3 and Activate Complement in AMD and in Models of Focal Retinal Degeneration, Invest Ophthalmol Vis Sci, 2017;58:2977-90.

36. Hageman GS, Anderson DH, Johnson LV, et al., A common haplotype in the complement regulatory gene factor $\mathrm{H}(\mathrm{HF} 1 / \mathrm{CFH})$ predisposes individuals to age-related macular degeneration, Proc Natl Acad Sci USA, 2005;102:7227-32.

37. Klein RJ, Zeiss $\mathrm{C}$, Chew EY, et al., Complement factor $\mathrm{H}$ polymorphism in age-related macular degeneration, Science, 2005;308:385-9.

38. Haines JL, Hauser MA, Schmidt S, et al., Complement factor $\mathrm{H}$ variant increases the risk of age-related macular degeneration science, 2005;308:419-21.

39. Edwards AO, Ritter R 3rd, Abel KJ, et al., Complement factor $\mathrm{H}$ polymorphism and age-related macular degeneration, Science, 
2005;308:421-4.

40. Stanton CM, Yates JR, den Hollander Al, et al., Complement factor D in age-related macular degeneration, Invest Ophthalmol Vis Sci, 2011;52:8828-34

41. van de Ven JPH, Nilsson SC, Tan P, et al., A functional variant in the CFI gene confers a high risk of age-related macular degeneration, Nat Genet, 2013;45:813-7.

42. Jakobsdottir J, Conley YP, Weeks DE, et al., C2 and CFB genes in age-related maculopathy and joint action with CFH and LOC387715 genes, PloS One, 2008;3:e2199.

43. Despriet DDG, Klaver CC, Witteman JC, et al., Complement factor $\mathrm{H}$ polymorphism, complement activators, and risk of age-related macular degeneration, JAMA, 2006:296:301-9.

44. US Census Bureau QuickFacts selected: UNITED STATES. Available at: www.census.gov/quickfacts/fact/table/US/ AGE775216\#viewtop (accessed October 12, 2017).

45. Hecker LA, Edwards AO, Ryu E, et al., Genetic control of the alternative pathway of complement in humans and age-related macular degeneration, Hum Mol Genet, 2010;19:209-15.

46. Kijlstra A, Berendschot TTJM, Age-Related Macular Degeneration: A Complementopathy? Ophthalmic Res, 2015;54:64-73.

47. Scholl HPN, Issa PC, Walier M, et al., Systemic Complement Activation in Age-Related Macular Degeneration, PLOS ONE 2008;3: 2593

48. Reynolds R, Hartnett ME, Atkinson JP, et al., Plasma complement components and activation fragments: associations with agerelated macular degeneration genotypes and phenotypes, Invest Ophthalmol Vis Sci, 2009:50:5818-27.

49. Lechner J, Chen M, Hogg RE, et al., Higher plasma levels of complement C3a, C4a and C5a increase the risk of subretinal fibrosis in neovascular age-related macular degeneration: Complement activation in AMD, Immun Ageing A, 2016;13:4

50. Smailhodzic D, Klaver CC, Klevering BJ, et al., Risk alleles in $\mathrm{CFH}$ and ARMS2 are independently associated with systemic complement activation in age-related macular degeneration, Ophthalmology, 2012;119:339-46.

51. Sivaprasad S, Adewoyin T, Bailey TA, et al., Estimation of systemic complement C3 activity in age-related macular degeneration, Arch Ophthalmol Chic III 1960, 2007;125:515-9.

52. van der Schaft TL, Mooy CM, de Bruijn WC, de Jong PT, Early stages of age-related macular degeneration: an immunofluorescence and electron microscopy study, $\mathrm{Br} \mathrm{J}$ Ophthalmol, 1993;77:657-61.

53. Baudouin C, Peyman GA, Fredj-Reygrobellet D, et al., Immunohistological study of subretinal membranes in age-related macular degeneration, Jpn J Ophthalmol, 1992;36:443-51.

54. Mullins RF, Schoo DP, Sohn EH, et al., The membrane attack complex in aging human choriocapillaris: relationship to macular degeneration and choroidal thinning, Am J Pathol 2014;184:3142-53.

55. Yehoshua Z, de Amorim Garcia Filho CA, Nunes RP, et al, Systemic complement inhibition with eculizumab for geographic atrophy in age-related macular degeneration: the COMPLETE study, Ophthalmology, 2014:121:693-701.

56. Garcia Filho CA de A, Yehoshua Z, Gregori G, et al., Change in drusen volume as a novel clinical trial endpoint for the study of complement inhibition in age-related macular degeneration, Ophthalmic Surg Lasers Imaging Retina, 2014;45:18-31.

57. A phase $2 / 3$ trial to assess the safety and efficacy of intravitreous administration of Zimura ${ }^{\circledR}$ (Anti-C5 Aptamer) in subjects with geographic atrophy secondary to dry age-related macular degeneration. ClinicalTrials.gov. Available at: https://clinicaltrials. gov/ct2/show/NCT02686658?term=ophthotech\&recrs=a\&rank= (accessed August 9, 2017)

58. Yaspan BL, Williams DF, Holz FG, et al., Targeting factor D of the alternative complement pathway reduces geographic atrophy progression secondary to age-related macular degeneration, $\mathrm{SC}$ Trans/ Med, 2017;9:pii: eaaf1443.

59. A Study Investigating the Efficacy and Safety of Lampalizumab Intravitreal Injections in Participants With Geographic Atrophy Secondary to Age-Related Macular Degeneration. ClinicalTrials. gov. Available at: https://clinicaltrials.gov/ct2/show/NCT02247479 (accessed August 9, 2017).

60. A Study Investigating the Safety and Efficacy of Lampalizumab Intravitreal Injections in Participants With Geographic Atrophy Secondary to Age-Related Macular Degeneration. ClinicalTrials. gov. Available at: https://clinicaltrials.gov/ct2/show/NCT02247531 (accessed August 9, 2017)

61. Safety of Intravitreal POT-4 Therapy for Patients With Neovascular Age-Related Macular Degeneration (AMD). ClinicalTrials.gov. Available at: https://clinicaltrials.gov/ct2/show/ NCT00473928? cond=POT-4\&rank=1 (accessed August 9, 2017).

62. Kaushal S, Grossi F, Francois C, et al., Complement C3 inhibito POT-4: Clinical Safety of Intravitreal Administration, Invest Ophthalmol Vis SCi, 2009:50:5010.

63. Efficacy, Safety And Tolerability Study Of RN6G In Subjects With Geographic Atrophy Secondary to Age-related Macular Degeneration. ClinicalTrials.gov. Available at: https://clinicaltrials. gov/ct2/show/NCT01577381 (accessed August 9, 2017).

64. Clinical Study to Investigate Safety and Efficacy of GSK933776 in Adult Patients With Geographic Atrophy Secondary to Agerelated Macular Degeneration. ClinicalTrials.gov. Available at: https://clinicaltrials.gov/ct2/show/NCT01342926 (accessed August 9, 2017).

65. Dentchev T, Milam AH, Lee VM, et al., Amyloid-beta is found in drusen from some age-related macular degeneration retinas, but not in drusen from normal retinas, Mol Vis, 2003;9:184-90.

66. Anderson DH, Talaga KC, Rivest AJ, et al., Characterization of beta amyloid assemblies in drusen: the deposits associated with aging and age-related macular degeneration, Exp Eye Res, 2004:78:243-56.

67. Tarallo V Hirano Y, Gelfand BD, et al., DICER1 loss and Alu RNA induce age-related macular degeneration via the NLRP3 inflammasome and MyD88, Cell, 2012;149:847-59.

68. Doyle SL, Campbell M, Ozaki E, et al., NLRP3 has a protective role in age-related macular degeneration through the induction of IL-18 by drusen components, Nat Med, 2012;18:791-8.

69. Doyle SL, Ozaki E, Brennan K, et al., IL-18 attenuates experimenta choroidal neovascularization as a potential therapy for wet agerelated macular degeneration, Sci Trans/ Med, 2014;6:230ra44.

70. Doyle SL, López FJ, Celkova L, et al., IL-18 Immunotherapy for Neovascular AMD: Tolerability and Efficacy in Nonhuman Primates, Invest Ophthalmol Vis Sci, 2015;56:5424-30.

71. Itahana K, Campisi J, Dimri GP, Methods to detect biomarkers of cellular senescence: the senescence-associated betagalactosidase assay, Methods Mol Biol Clifton NJ, 2007;371:21-31.

72. Debacq-Chainiaux F, Erusalimsky JD, Campisi I, Toussaint O Protocols to detect senescence-associated beta-galactosidase (SA-betagal) activity, a biomarker of senescent cells in culture and in vivo, Nat Protoc, 2009;4:1798-806.

73. Dimri GP, Lee X, Basile G, et al., A biomarker that identifies senescent human cells in culture and in aging skin in vivo, Proc Natl Acad Sci USA, 1995:92:9363-7.

74. van der Loo B, Fenton MJ, Erusalimsky JD, Cytochemical detection of a senescence-associated beta-galactosidase in endothelial an smooth muscle cells from human and rabbit blood vessels, Exp Cell Res, 1998;241:309-15.

75. Mishima K, Handa JT, Aotaki-Keen A, et al., Senescenceassociated beta-galactosidase histochemistry for the primate eye, Invest Ophthalmol Vis Sci, 1999;40:1590-3.

76. Freund A, Patil CK, Campisi J, p38MAPK is a novel DNA damage response-independent regulator of the senescence-associated secretory phenotype, EMBO J, 2011;30:1536-48.

77. Salminen A, Kauppinen $A$, Kaarniranta $K$, Emerging role of NF-KB signaling in the induction of senescence-associated secretory phenotype (SASP), Cell Signal, 2012;24:835-45.

78. Childs BG, Baker DJ, Kirkland JL, et al., Senescence and apoptosis: dueling or complementary cell fates?, EMBO Rep, 2014:15:1139-53

79. Jun J-I, Lau LF, Cellular senescence controls fibrosis in wound healing, Aging, 2010;2:627-31.

80. Jun J-I, Lau LF, The matricellular protein CCN1 induces fibroblast senescence and restricts fibrosis in cutaneous wound healing Nat Cell Biol, 2010;12:676-85.

81. Adams PD, Healing and hurting: molecular mechanisms, functions, and pathologies of cellular senescence, $\mathrm{Mol}$ Cell, 2009:36:2-14.

82. Pérez-Mancera PA, Young ARJ, Narita M, Inside and out: the activities of senescence in cancer, Nat Rev Cancer, 2014;14:547-58.

83. Lujambio A, To clear, or not to clear (senescent cells)? That is the question, BioEssays News Rev Mol Cell Dev Biol, 2016;38(Suppl 1):S56-64

84. Kozlowski MR, RPE cell senescence: a key contributor to agerelated macular degeneration, Med Hypotheses, 2012;78:505-10.

85. Han S, Lu Q, Wang N, Apr3 accelerates the senescence of human retinal pigment epithelial cells, Mol Med Rep, 2016;13:3121-6.

86. Chen $\mathrm{H}$, Lukas TJ, Du N, et al., Dysfunction of the retinal pigment epithelium with age: increased iron decreases phagocytosis and Iysosomal activity, Invest Ophthalmol Vis Sci, 2009;50:1895-902.

87. Matsunaga H, Handa JT, Aotaki-Keen A, et al., Beta-galactosidase histochemistry and telomere loss in senescent retinal pigment epithelial cells, Invest Ophthalmol Vis Sci, 1999;40:197-202.

88. Matsunaga $\mathrm{H}$, Handa JT, Gelfman CM, Hjelmeland LM, The mRNA phenotype of a human RPE cell line at replicative senescence, Mol Vis, 1999;5:39

89. Glotin A-L, Debacq-Chainiaux F, Brossas JY, et al., Prematurely senescent ARPE-19 cells display features of age-related macular degeneration, Free Radic Biol Med, 2008;44:1348-61

90. Feng $L$, Cao $L$, Zhang $Y$, Wang $F$, Detecting $A \beta$ deposition and RPE cell senescence in the retinas of SAMP8 mice, Discov Med, 2016;21:149-58.

91. Carmona-Gutierrez D, Hughes AL, Madeo F, Ruckenstuhl C, The crucial impact of lysosomes in aging and longevit, Ageing Res Rev, 2016;32:2-12.

92. Huang J, Xu J, Pang S, et al., Age-related decrease of the LAMP-2 gene expression in human leukocytes, Clin Biochem, 2012;45:1229-32

93. Lacoste-Collin L, Garcia V, Uro-Coste E, et al., Danon's disease (X-linked vacuolar cardiomyopathy and myopathy): a case with a novel Lamp-2 gene mutation, Neuromuscul Disord NMD, 2002;12:882-5.

94. Schorderet DF, Cottet S, Lobrinus JA, et al., Retinopathy in Danon disease, Arch Ophthalmol Chic III 1960, 2007;125:231-6.

95. Prall FR, Drack A, Taylor M, et al., Ophthalmic manifestations of Danon disease, Ophthalmology, 2006;113:1010-3.

96. Thiadens AAHJ, Slingerland NW, Florijn RJ, et al., Cone-rod dystrophy can be a manifestation of Danon disease, Graefes Arch Clin Exp Ophthalmol, 2012;250:769-74.

97. Notomi S, et al., Dysfunctional autophagosome and phagosome in age-related macular degeneration (AMD), Invest Ophthalmol Vis Sci, 2015;56:3537.
98. Dib B, Lin H, Maidana DE, et al., Mitochondrial DNA has a pro-inflammatory role in AMD, Biochim Biophys Acta 2015; 1853:2897-906

99. Feher J, Kovacs I, Artico M, et al., Mitochondrial alterations of retinal pigment epithelium in age-related macular degeneration, Neurobiol Aging, 2006;27:983-93.

100. Terluk MR, Kapphahn RJ, Soukup LM, et al., Investigating mitochondria as a target for treating age-related macular degeneration, J Neurosci Off J Soc Neurosci, 2015;35:7304-11.

101. Wang AL, Lukas TJ, Yuan M, Neufeld AH, Increased mitochondrial DNA damage and down-regulation of DNA repair enzymes in aged rodent retinal pigment epithelium and choroid, Mol Vis, 2008:14:644-51.

102. Karunadharma PP, Nordgaard CL, Olsen TW, Ferrington DA Mitochondrial DNA damage as a potential mechanism for age-related macular degeneration, Invest Ophthalmol Vis SCi, 2010;51:5470-9.

103. Lin $\mathrm{H}$, XU H, Liang FQ, et al., Mitochondrial DNA damage and repair in RPE associated with aging and age-related macula degeneration, Invest Ophthalmol Vis Sci, 2011:52:3521-9.

104. Lin H, Tian B, Moujahed AA, et al., Accumulation of damaged nDNA promotes RPE cellular senescence and pro-inflammation, Invest Ophthalmol Vis Sci, 2017;58:5235.

105. Mimura T, Kaji Y, Noma H, et al., The role of SIRT1 in ocular aging, Exp Eye Res, 2013;116:17-26.

106. Balaiya S, Abu-Amero KK, Kondkar AA, Chalam KV, Sirtuins Expression and Their Role in Retinal Diseases, Oxid Med Cell Longev, 2017;3187594.

107. Mihaylova MM, Shaw RJ, The AMP-activated protein kinase (AMPK) signaling pathway coordinates cell growth, autophagy, \& metabolism, Nat Cell Biol, 2011;13:1016-23.

108. Zhou G, Myers R, Li Y, et al., Role of AMP-activated protein kinase in mechanism of metformin action, $J$ Clin Invest, 2001;108:1167-

109. Imai S, SIRT1 and Caloric Restriction: An Insight Into Possible Trade-Offs Between Robustness and Frailty, Curr Opin Clin Nutr Metab Care, 2009:12:350-6.

110. Cantó C, Auwerx J, Caloric restriction, SIRT1 and longevity, Trends Endocrinol Metab TEM, 2009;20:325-31

111. Ruderman NB, XU XJ, Nelson L, et al., AMPK and SIRT1: long-standing partnership?, Am J Physiol Endocrinol Metab 2010;298:E751-60

112. Martin B, Mattson MP, Maudsley S, Caloric restriction and intermittent fasting: Two potential diets for successful brain aging, Ageing Res Rev, 2006;5:332-53.

113. Cantó C, Auwerx J, Calorie restriction: is AMPK as a key sensor and effector?, Physiol Bethesda Md, 2011;26:214-24.

114. López-Lluch G, Navas P, Calorie restriction as an intervention in ageing, J Physiol, 2016;594:2043-60.

115. Chen Z, Zhai Y, Zhang W, et al., Single Nucleotide Polymorphisms of the Sirtuin 1 (SIRT1) Gene are Associated With age-Related Macular Degeneration in Chinese Han Individuals: A Case-Control Pilot Study, Medicine (Baltimore), 2015;94:e2238.

116. Golestaneh N, Chu Y, Cheng SK, et al., Repressed SIRT1/PGC-1 pathway and mitochondrial disintegration in IPSC-derived RPE disease model of age-related macular degeneration, I Trans/ Med 2016;14:344

117. Kaarniranta K, Kauppinen A, Blasiak J, Salminen A, Autophagy regulating kinases as potential therapeutic targets for age-related macular degeneration, Future Med Chem, 2012;4:2153-61.

118. Hyttinen JMT, Petrovski G, Salminen A, Kaarniranta K, $5^{\prime}$-Adenosine monophosphate-activated protein kinase--mammalian target of rapamycin axis as therapeutic target for age-related macular degeneration, Rejuvenation Res, 2011:14:651-60.

119. Qin S, De Vries GW, alpha2 But not alpha1 AMP-activated protein kinase mediates oxidative stress-induced inhibition of retina pigment epithelium cell phagocytosis of photoreceptor outer segments, J Biol Chem, 2008;283:6744-51.

120. Samuel MA, et al., LKB1 and AMPK regulate synaptic remodeling in old age, Nat Neurosci, 2014:17:1190-7.

121. Talks JS, Lotery AJ, Ghanchi F, et al., First-year visual acuity outcomes of providing aflibercept according to the VIEW Study protocol for age-related macular degeneration, Ophthalmology 2016;123:337-43.

122. Heier JS, Brown DM, Chong V, et al., Intravitreal aflibercept VEGF trap-eye) in wet age-related macular degeneration, Ophthalmology, 2012;119:2537-48

123. Rosenfeld PJ, Brown DM, Heier JS, et al., Ranibizumab for neovascular age-related macular degeneration, $N$ Engl I Med, 2006;355:1419-31.

124. CATT Research Group, Ranibizumab and bevacizumab for neovascular age-related macular degeneration, N Eng/ I Med, 2011;364:1897-908.

125. Brown DM, Kaiser PK, Michels M, Ranibizumab versus verteporfin for neovascular age-related macular degeneration, N Engl I Med, 2006;355:1432-44

126. Comparison of Age-related Macular Degeneration Treatments Trials (CAT) Research Group, Maguire MG, Martin DF, et al., Five-year outcomes with anti-vascular endothelial growth factor treatment of neovascular age-related macular degeneration: the comparison of age-related macular degeneration treatments trials, Ophthalmology, 2016;123:1751-61.

127. Rofagha S, et al., Seven-year outcomes in ranibizumab-treated patients in ANCHOR, MARINA, and HORIZON: a multicenter cohort study (SEVEN-UP), Ophthalmology, 2013;120:2292-9.

128. Singer MA, et al., HORIZON: an open-label extension trial of 
ranibizumab for choroidal neovascularization secondary to agerelated macular degeneration, Ophthalmology, 2012:119:1175-83.

129. Qin VL, Young J, Silva FQ, et al., Outcomes of patients with exudative age-related macular degeneration treated with antivascular endothelial growth factor therapy for three or more years: A review of current outcomes, Retina Phila Pa, 2017. doi:10.1097/IAE.0000000000001753

130. Holekamp NM, Liu Y, Yeh WS, et al., Clinical utilization of anti-VEGF agents and disease monitoring in neovascular age-related macular degeneration, Am J Ophthalmol, 2014;157:825-833.e1.

131. Channa R, Sophie R, Bagheri S, et al., Regression of choroidal neovascularization results in macular atrophy in anti-vascular endothelial growth factor-treated eyes, Am J Ophthalmol, 2015;159:9-19.e1-2

132. McLeod DS, Taomoto M, Otsuji T, et al., Quantifying changes in RPE and choroidal vasculature in eyes with age-related macular degeneration, Invest Ophthalmol Vis Sci, 2002;43:1986-93.

133. Prenner JL, Halperin LS, Rycroft C, et al., Disease Burden in the Treatment of Age-Related Macular Degeneration: Findings From a Time-and-Motion Study, Am J Ophthalmol, 2015:160:725-731.e1.

134. Novartis RTH258 (brolucizumab) demonstrates robust visual gains in nAMD patients with a majority on a 12-week injection interval. Available at: www.novartis.com/news/media-releases/novartisrth258-brolucizumab-demonstrates-robust-visual-gains-namdpatients (accessed 12 October 2017).

135. Dugel PU, et al., Brolucizumab Versus Aflibercept in Participants with Neovascular Age-Related Macular Degeneration: A Randomized Trial, Ophthalmology, 2017; doi:10.1016/j. ophtha.2017.03.057.

136. Efficacy and Safety of RTH258 Versus Aflibercept. ClinicalTrials. gov. Available at: https://clinicaltrials.gov/ct2/show/ NCT02307682?term=RTH258\&rank=3 (accessed August 11, 2017).

137. Efficacy and Safety of RTH258 Versus Aflibercept - Study 2. ClinicalTrials.gov. Available at: https://clinicaltrials.gov/ct2/show/ NCT02434328?term=RTH258\&rank=2 (accessed August 11, 2017).

138. Study of the efficacy and safety of the ranibizumab port delivery system (RPDS) for sustained delivery of ranibizumab in participants with subfoveal neovascular age-related macular degeneration (AMD) (LADDER). ClinicalTrials.gov. Available at: https://clinicaltrials.gov/ct2/show/NCT02510794 (accessed September 18, 2017).

139. Ocular Therapeutix, Inc. "Intravitreal Depots." Available at: www.ocutx.com/pipeline/intravitreal-depots (accessed September 16, 2017).

140. Schachat AP, Wilkinson CP, Hinton DR, et al., Ryan's Retina E-Book, Elsevier Health Sciences, 2017.

141. Park DY, Lee J, Kim J, et al., Plastic roles of pericytes in the bloodretinal barrier, Nat Commun, 2017;8:15296

142. Helfrich I, Schadendorf D, Blood vessel maturation, vascular phenotype and angiogenic potential in malignant melanoma: one step forward for overcoming anti-angiogenic drug resistance? Mol Oncol, 2011:5:137-49.

143. Shen J, Frye M, Lee BL, et al., Targeting VE-PTP activates TIE2 and stabilizes the ocular vasculature, J Clin Invest, 2014:124:4564-76.

144. Maisonpierre PC, Suri C, Jones PF, et al., Angiopoietin-2, a natural antagonist for Tie2 that disrupts in vivo angiogenesis, Science, 1997;277:55-60.

145. Ng DS, Yip YW, Bakthavatsalam M, et al., Elevated angiopoietin 2 in aqueous of patients with neovascular age related macular degeneration correlates with disease severity at presentation, Sci Rep, 2017:7:45081.

146. Ma L, Brelen ME, Tsujikawa M, et al., Identification of ANGPT2 as a
New Gene for Neovascular Age-Related Macular Degeneration and Polypoidal Choroidal Vasculopathy in the Chinese and Japanese Populations, Invest Ophthalmol Vis Sci, 2017:58:1076-83.

147. Otani $\mathrm{A}$, Takagi $\mathrm{H}$ Oh $\mathrm{H}$, et al Expressions of angiopoietins and Tie2 in human choroidal neovascular membranes, Invest Ophthalmol Vis Sci, 1999;40:1912-20.

148. Hera R, Keramidas M, Peoc'h M, et al., Expression of VEGF and angiopoietins in subfoveal membranes from patients with age-related macular degeneration, Am J Ophthalmol 2005;139:589-96

149. Nambu H, Nambu R, Oshima Y, et al., Angiopoietin 1 inhibits ocular neovascularization and breakdown of the blood-retinal barrier, Gene Ther, 2004:11:865-73.

150. Thurston G, Suri C, Smith K, et al., Leakage-resistant blood vessels in mice transgenically overexpressing angiopoietin-1, Science, 1999;286:2511-4

151. Thurston G, Rudge JS, loffe E, et al., Angiopoietin-1 protects the adult vasculature against plasma leakage, Nat Med, 2000;6:460-3

152. Campochiaro PA Khanani A Singer $M$ et al Enhanced Benefit in Diabetic Macular Edema from AKB-9778 Tie2 Activation Combined with Vascular Endothelial Growth Factor Suppression, Ophthalmology, 2016;123:1722-30.

153. D' Angelo SP, Mahoney MR, Van Tine BA, et al., Alliance A091103 a phase II study of the angiopoietin 1 and 2 peptibody trebananib for the treatment of angiosarcoma, Cancer Chemothe Pharmacol, 2015;75:629-38.

154. Regula JT, Lundh von Leithner P, Foxton R, et al., Targeting key angiogenic pathways with a bispecific CrossMAb optimized for neovascular eye diseases, EMBO Mol Med, 2016:8:1265-88.

155. Zacks DN, Hänninen V, Pantcheva M, et al., Caspase activation in an experimental model of retinal detachment, Invest Ophthalmo Vis SCi, 2003;44:1262-7

156. Zacks DN, Zheng Q-D, Han Y, et al., FAS-mediated apoptosis and its relation to intrinsic pathway activation in an experimental model of retinal detachment, Invest Ophthalmol Vis Sci, 2004;45:4563-9.

157. Zacks DN, Han Y, Zeng Y, Swaroop A, Activation of signaling pathways and stress-response genes in an experimental model of retinal detachment, Invest Ophthalmol Vis Sci, 2006;47:1691-5.

158. Murakami Y, Notomi S, Hisatomi T, et al., Photoreceptor cell death and rescue in retinal detachment and degenerations, Prog Retin Eye Res, 2013;37:114-40.

159. Huckfeldt RM, Vavvas DG, Neuroprotection for retinal detachment, Int Ophthalmol Clin, 2013;53:105-17.

160. Matsumoto H, Murakami Y, Kataoka K, et al., Membrane-bound and soluble Fas ligands have opposite functions in photoreceptor cell death following separation from the retinal pigment epithelium, Cell Death Dis, 2015;6:e1986.

161. Mantopoulos, D, Murakami Y, Comander J, et al., Tauroursodeoxycholic acid (TUDCA) protects photoreceptors from cell death after experimental retinal detachment, Plos One, 2011;6:e24245.

162. Nakazawa T, Matsubara A, Noda K, et al., Characterization of cytokine responses to retinal detachment in rats, Mol Vis, 2006;12:867-78.

163. Murakami Y, Miller JW, Vavvas DG, RIP kinase-mediated necrosis as an alternative mechanisms of photoreceptor death, Oncotarget, 2011;2:497-509.

164. Nakazawa T, Kayama M, Ryu M, et al., Tumor necrosis factor-alpha mediates photoreceptor death in a rodent model of retinal detachment, Invest Ophthalmol Vis Sci, 2011:52:1384-91.

165. Kayama M, Nakazawa T, Thanos A, et al., Heat shock protein 70
(HSP70) is critical for the photoreceptor stress response after retinal detachment via modulating anti-apoptotic Akt kinase, Am J Pathol, 2011:178:1080-91.

166. Roh MI, Murakami Y, Thanos A, et al., Edaravone, an ROS scavenger, ameliorates photoreceptor cell death after experimental retinal detachment, Invest Ophthalmol Vis Sci, 2011;52:3825-31.

167. Trichonas G, Murakami Y, Thanos A, et al., Receptor interacting protein kinases mediate retinal detachment-induced photoreceptor necrosis and compensate for inhibition of apoptosis, Proc Natl Acad Sci USA, 2010:107:21695-700.

168. Hisatomi T, Sakamoto T, Murata T, et al., Relocalization of apoptosis-inducing factor in photoreceptor apoptosis induced by retinal detachment in vivo, Am J Pathol, 2001:158:1271-8.

169. Schweichel JU, Merker HJ, The morphology of various types of cell death in prenatal tissues, Teratology, 1973;7:253-66.

170. Degterev A, Huang Z, Boyce M, et al., Chemical inhibitor of nonapoptotic cell death with therapeutic potential for ischemic brain injury, Nat Chem Biol, 2005;1:112-9.

171. Chan FK-M, Shisler J, Bixby JG, et al., A role for tumor necrosis factor receptor-2 and receptor-interacting protein in programmed necrosis and antiviral responses, J Biol Chem, 2003;278:51613-21.

172. Kataoka K, Matsumoto $\mathrm{H}$, Kaneko $H_{\text {, et al., Macrophage- and }}$ RIP3-dependent inflammasome activation exacerbates retinal detachment-induced photoreceptor cell death, Cell Death Dis, 2015;6:e1731

173. Matsumoto H, Kataoka K, Tsoka P, et al., Strain difference in photoreceptor cell death after retinal detachment in mice, Invest Ophthalmol Vis Sci, 2014:55:4165-74.

174. Murakami Y, Matsumoto H, Roh M, et al., Programmed necrosis, not apoptosis, is a key mediator of cell loss and DAMP-mediated inflammation in dsRNA-induced retinal degeneration, Cell Death Differ, 2014;21:270-7.

175. Kim LA, Amarnani D, Gnanaguru G, et al., Tamoxifen toxicity in cultured retinal pigment epithelial cells is mediated by concurrent regulated cell death mechanisms, Invest Ophthalmol Vis sci, 2014:55:4747-58.

176. Schmitz-Valckenberg S, Sahel JA2, Danis R, et al., Natural history of geographic atrophy progression secondary to age-related macular degeneration (Geographic Atrophy Progression Study), Ophthalmology, 2016;123:361-8.

177. Del Priore LV, Kuo Y-H, Tezel TH, Age-related changes in human RPE cell density and apoptosis proportion in situ, Invest Ophthalmol Vis Sci, 2002:43:3312-8.

178. Boey PY, Tay WT, LamoureuX E, et al., C-reactive protein and agerelated macular degeneration and cataract: the singapore malay eye study, Invest Ophthalmol Vis Sci, 2010;51:1880-5.

179. MCGwin G, Hall TA, Xie A, Owsley C, The relation between $C$ reactive protein and age related macular degeneration in the Cardiovascular Health Study, Br I Ophthalmol, 2005;89:1166-70.

180. Pinna A, Zaccheddu F, Boscia F, et al., Homocysteine and risk of age-related macular degeneration: a systematic review and meta-analysis, Acta Ophthalmol (Copenh), 2016; doi:10.1111/ aos. 13343 .

181. Laíns I, Duarte D, Barros AS, et al., Human plasma metabolomics in age-related macular degeneration (AMD) using nuclear magnetic resonance spectroscopy, PLOS ONE, 2017;12:e0177749

182. Laíns I, Kelly RS, Miller JB, et al., Human Plasma Metabolomics Study across All Stages of Age-Related Macular Degeneration Identifies Potential Lipid Biomarkers, Ophthalmology, 2017; doi:10.1016/j.ophtha.2017.08.008 